\title{
Theoretical insights into the nature of synergistic enhancement in bimetallic CoTiAIPO-5 catalysts for ammonia activation
}

Received 00th January 20xx, Accepted 00th January 20xx

DOI: $10.1039 / \times 0 \times x 00000 x$

www.rsc.org/

\author{
M. E. Potter, ${ }^{a *}$ K. McColl, ${ }^{b}$ F. Corà, ${ }^{b}$ A. B. Levy ${ }^{c}$ and R. Raja ${ }^{a}$
}

Bimetallic catalytic synergy, the concurrent action of two different metal ions in the same material, has resulted in improved efficiency in many catalytic systems and for a range of chemical processes. Via a computational mechanistic study, we investigate the catalytic benefits of the bimetallic CoTiAIPO-5 material in comparison to the monometallic CoAIPO-5 system, on the activation of $\mathrm{NH}_{3}$. The presence of $\mathrm{Ti}$ in a framework site adjacent to Co stabilises the Co(II) oxidation state, and increases the $\mathrm{Co}(\mathrm{III}) / \mathrm{Co}(\mathrm{II})$ reduction potential. We show that this change lowers the activation barrier for the homolytic $\mathrm{H}$ extraction from $\mathrm{NH}_{3}$ by $\mathrm{Co}(\mathrm{III})$, from $162 \mathrm{~kJ} / \mathrm{mol}$ in the monometallic CoAIPO-5 catalyst to $140 \mathrm{~kJ} / \mathrm{mol}$ in the bimetallic CoTiAIPO-5 (175 and $111 \mathrm{~kJ} / \mathrm{mol}$ respectively when considering both dispersion and free energy corrections). Elucidation of mechanistic details through computational studies can make significant contributions to the rational design of catalytic materials.

\section{Introduction}

The development of novel catalytic systems is fundamental in the pursuit of sustainable chemical processes. To maximise catalytic efficacy, a range of factors and structure-property correlations must be conscientiously modulated, through rigorous and adroit synthetic protocols. ${ }^{1-9}$ The rational design of novel bimetallic heterogeneous catalysts has received significant attention; recent successes, including nanoparticles, ${ }^{3}$ mixed metal oxides ${ }^{4}$ and metal dopants, ${ }^{5}$ demonstrate that the intrinsic behaviour of an active metal centre can be attuned by a second metal site. ${ }^{1-9}$ However the second metal site garners further levels of complexity, introducing new metal-framework and metal-metal interactions. Yet, knowledge of these interactions is necessary towards intelligent and rational catalytic design. ${ }^{1,8}$

Numerous examples show the catalytic advantages of bimetallic substitution in aluminophosphate (AIPO) frameworks. AlPOs consist of alternating $\mathrm{Al}(\mathrm{III})$ and $\mathrm{P}(\mathrm{V})$ oxidic corner-sharing tetrahedra, forming structures akin to zeolites. A range of different dopants can be introduced into the frameworks, based on oxidation state and ionic radius, allowing many metallic substituent pairings for different chemical processes. ${ }^{10-14}$ Recently we performed a combined experimental and computational (X-ray Adsorption Spectroscopy and periodic Density Functional Theory) study to probe the nature of the synergistic enhancement within the CoTiAIPO-5 catalyst (where both cobalt and titanium ions are isomorphously substituted into the same AIPO- 5 framework). ${ }^{13,14}$ The improved catalytic activity has been attributed to the close proximity of the cobalt

\footnotetext{
a. Department of Chemistry, University of Southampton, Department of Chemistry, University Road, Southampton, Hants, SO17 1BJ, UK.

b. Department of Chemistry, University College London, 20 Gordon Street, London, WC1H OAJ, UK.

Honeywell Int, 101 Columbia Road, Morristown, NJ 07962, USA.

*M.E.Potter@soton.ac.uk

Electronic Supplementary Information (ESI) available: This includes geometric information on monometallic and bimetallic systems. Coordination geometries of ammonia-bound species, energy profile of non-catalytic ammonia activation, $\Gamma$ point phonon modes for the transition states, further figures on the evolution of bond lengths and spin for the radical formation and radical stabilization steps. See DOI: $10.1039 / x 0 x x 00000 x$
}

and titanium dopants. The metal pairing was initially found to make the $\mathrm{Ti}(\mathrm{IV})$ ions increasingly tetrahedral, compared to monometallic TiAIPO-5. This is notable as a tetrahedral geometry has been found to aid oxidant activation in other titanium-containing materials including TS-1 and Ti-MCM41. ${ }^{15,16}$ This study also demonstrated that a significant proportion of the cobalt and titanium atoms are in adjacent framework sites, forming a distorted Co-O-Ti bridge. The presence of the adjacent titanium was found to modify the III/II redox energy of the framework cobalt ions, from -1.2 to $-1.7 \mathrm{eV}$ using $\mathrm{H}_{2}$ as reductant (Figure 1), accounting for improvements in oxidation catalysis. ${ }^{13,14,17-19}$.

Theoretical studies play a significant role in understanding monometallic active sites in zeotype catalysts. ${ }^{20-24}$ Primarily these studies focus on the properties and characteristics of metal species, ${ }^{20-22}$ with more recent studies probing the mechanistic pathways, for example of hydrocarbon activation. ${ }^{23-25}$ Scarce few studies have addressed the features of bimetallic species. ${ }^{2,25}$ In this work we employ electronic structure calculations to investigate the likely initial stages of the activation of ammonia, and contrast the behaviour of cobalt in monometallic CoAIPO-5 and in the bimetallic CoTiAIPO-5.

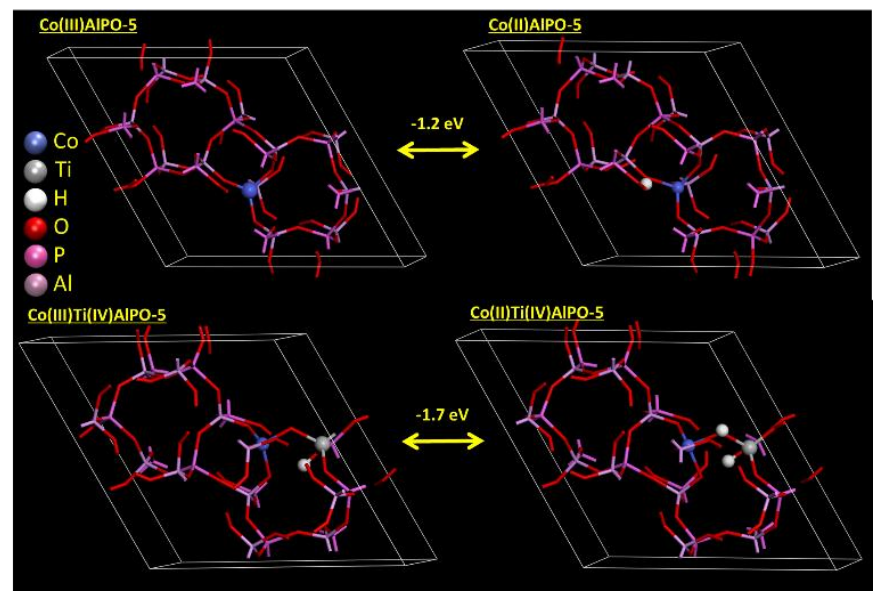

Figure 1. Illustration of the titanium ability to attune the redox properties of COAIPO-5. Redox potentials are calculated as the energy change in: Co(III)AIPO-5 $+1 / 2 \mathrm{H}_{2} \rightarrow \mathrm{H}-\mathrm{Co}(\mathrm{II})$ AlPO-5 as per reference 17 . 
On obtaining a deeper appreciation of the mechanistic processes it is believed that the results yielded here will aid the future rational design of catalytic systems. In situ production of $\mathrm{NH}_{2} \mathrm{OH}$ from $\mathrm{NH}_{3}$ is critical for processes of industrial relevance, such as the ammoximation of cyclohexanone to $\varepsilon$-caprolactam, an important precursor for the production of nylon- $6 .{ }^{18}$

\section{Experimental section}

Periodic Density Functional Theory (DFT) electronic structure calculations were performed on the University of Southampton Iridis3 and the UK national HPC service Archer, using the same setup discussed in detail in reference 14 . We used the CRYSTAL code $^{26}$ and the B3LYP hybrid-exchange functional. ${ }^{27-30}$ The AFI framework was calculated using periodic boundary conditions in P1 space group to allow full-optimisation without symmetry constraints. The electronic distribution was described as a linear combination of atomic orbitals and the basis functions are expressed as Gaussian-type orbitals. Aluminium, phosphorus, oxygen and hydrogen ions were described using a double valence plus polarization basis set whereas titanium and cobalt were described using a triple-valence plus polarization basis set. All basis sets employed were taken from the online library for the CRYSTAL code. ${ }^{31}$ The AFI structure was described by modelling one unit cell containing 72 atoms (12 $\mathrm{AlPO}_{4}$ formula units). ${ }^{14}$ Cobalt was substituted for aluminium and titanium was substituted for phosphorus. In the case of a charge imbalance (Co(II) substituting $\mathrm{Al}(\mathrm{III})$ or $\mathrm{Ti}(\mathrm{IV})$ substituting for $\mathrm{P}(\mathrm{V})$ ) a proton was attached to an oxygen ion adjacent to the divalent or tetravalent dopant. One substitution was made per metal per unit cell, corresponding to $8.3 \mathrm{~mol} \%$ loading. ${ }^{14}$ In all cases the high-spin configuration was found to be the ground electronic state. The initial geometries were taken from our previous work, where all possible positions of charge balancing protons and adjacent titanium atom were calculated with the unit cell parameters left unconstrained. ${ }^{14}$ The lowest energy combinations were selected and used in this work. In this work the unit cell parameters were kept constant for calculating the energy of the system. Transition state geometries were obtained by calculating the internal energy of the system along the relevant reaction coordinates through constrained

geometry optimizations where the reaction coordinate was fixed and all other degrees of freedom allowed to relax. The reaction coordinate has been varied in steps of $0.1 \AA$ or less, between its value in reagent and products. Transition state geometries, identified as the local internal energy maximum along the reaction coordinate, have been refined via second derivative methods and eigenvector-following modes. In all cases we found the initial constrained calculations reproduce the correct transition state to within $0.1 \mathrm{~kJ} / \mathrm{mol}$ in energy and $0.01 \AA$ in geometry.

Internal energies have been corrected for an estimate of dispersion through the empirical scheme proposed by Grimme. ${ }^{32}$ Vibrational contributions (zero point energy and vibrational entropy) have also been added to reagents, products and transition states to estimate the reaction free energies at room temperature.

\section{Results and discussions}

\section{Internal energies}

In this section we report and discuss results concerning the internal energies calculated at B3LYP level. Dispersion and free energy corrections from vibrational modes are considered in section 2.

The activation of ammonia to form hydroxylamine $\left(\mathrm{NH}_{2} \mathrm{OH}\right)$ occurs through aerobic oxidation of ammonia with molecular oxygen. ${ }^{18,19}$ For the first step in our mechanistic study we have therefore investigated the binding of these reagents on the monometallic catalysts: Ti(IV)AIPO-5 and Co(II/III)AIPO-5, whose geometric structures are summarized in Tables S1-S5, further details in reference 14 . Neither metal showed significant interaction with molecular oxygen (less than $13 \mathrm{~kJ} / \mathrm{mol}$, Table 1), and both oxygen atoms reside at least $3.0 \AA$ away from the metal center in all cases. The slight energetic stabilization observed is in the region expected for Van der Waals interactions between a molecule and a pore wall (Table 1 , Tables S6-S8)..$^{33}$

In contrast all metal ions interact with ammonia (Table 1 and Tables S9-S11), through the Lewis acid/base interaction between the lone pair of electrons on the nitrogen and the electron-deficient metal centre; adsorption on the metal is favoured over interaction with the Brønsted acid protons. This was confirmed by using a range of initial geometries of ammonia within the unit cell, all of which eventually converged on a $\mathrm{M}-\mathrm{NH}_{3}$ bond regardless of whether ammonia was placed near a Brønsted acid site for all systems.

This behavior is analogous to that of ethane in MnAIPO-5. ${ }^{23,24}$ The binding energy increases with the metal oxidation state, as the metal becomes increasingly electron deficient and molecule. Interaction between ammonia and the bimetallic Co(III)Ti(IV)AIPO-5 showed ammonia preferentially bound to cobalt, not titanium (Table 2, Tables S12 and S13), in contrast to

Table 1 Binding energies and metal-N/O distance of ammonia and oxygen with specific metal centres in the monometallic catalysts.

\begin{tabular}{ccccc}
\hline \multirow{2}{*}{ System } & $\begin{array}{c}\text { Binding } \\
\text { energy/ } \\
\left(\mathrm{kJ} \mathrm{mol}^{-1}\right)^{\mathrm{a}}\end{array}$ & $\begin{array}{c}\mathrm{M}-\mathrm{NH}_{3} \\
\text { distance/A }\end{array}$ & $\begin{array}{c}\text { Binding } \\
\text { energy/ } \\
\left(\mathrm{kJ} \mathrm{mol}^{-1}\right)\end{array}$ & $\begin{array}{c}\mathrm{M}-\mathrm{O}_{2} \\
\text { distance/ }\end{array}$ \\
\hline Co(II)AIPO-5 & -56.1 & 2.22 & -4.7 & 3.22 \\
Co(III)AIPO-5 & -63.4 & 2.21 & -6.0 & 3.42 \\
Ti(IV)AIPO-5 & -107.9 & 2.25 & -12.3 & 3.00 \\
\hline
\end{tabular}

Table $2 \mathrm{NH}_{3}$ binding energies and metal-N distance in $\mathrm{Co}(\mathrm{III}) \mathrm{Ti}(\mathrm{IV}) \mathrm{AIPO}-5$.

\begin{tabular}{ccc} 
Atom bound to $\mathrm{NH}_{3}$ & Binding energy $/\left(\mathrm{kJ} \mathrm{mol}^{-1}\right)^{\mathrm{a}}$ & $\mathrm{M}-\mathrm{N}$ distance $/ \AA$ \\
\hline $\mathrm{Co}(\mathrm{III})$ & -82.2 & 2.19 \\
$\mathrm{Ti}(\mathrm{IV})$ & -32.8 & 2.23 \\
\hline
\end{tabular}

a) Binding energy was calculated thus:

$E_{\text {Binding }}=E\left[M^{n+} A I P O-5+\right.$ Probe $]-E\left[M^{n+} A I P O-5\right]-E[P r o b e]$ 
therefore a better acceptor for the $\sigma$-donating ammonia the trend observed for the monometallic systems (Table 1). While the adsorption energy of ammonia on Co(III) increases from $63.4 \mathrm{~kJ} \mathrm{~mol}^{-1}$ in the monometallic catalyst to -82.2 in the bimetallic, the adsorption energy for Ti decreases from -107.9 to -32.8 , despite showing similar $\mathrm{M}-\mathrm{NH}_{3}$ bond distances to the monometallic species. This is therefore primarily due to the local environment around $\mathrm{Co}$ and $\mathrm{Ti}$ before and after the binding process. Before interacting with $\mathrm{NH}_{3} \mathrm{Co}(\mathrm{III})$ adopts a distorted tetrahedral environment, with one bond (1.93 $\AA$ ) clearly longer than the other three (1.86, 1.76 and $1.74 \AA$ A). On binding to the $\mathrm{NH}_{3}$ a trigonal bipyramidal environment evolves around the cobalt center (Figure S1), where the longer bond extends, naturally adopting the axial position trans to $\mathrm{NH}_{3}$. In contrast the Ti(IV) environment is made of two short bonds (1.74 and $1.77 \AA$ ) and two longer bonds ( 1.93 and $1.98 \AA$ ). Our previous work showed that these two longer bonds are due to the distortion associated with the Co-O-Ti bridge (1.93 Å) and the protonated oxygen in the Ti-OH-Al species (1.98 $\AA$ ). Therefore to accommodate the ammonia, the already distorted Co-O-Ti and Ti-OH-Al bonds would have to distort further still, extending the bond lengths and weakening the interactions. This would result in a less energetically favourable system. The bimetallic cobalt site, in comparison, only has one distorted bond to accommodate, hence why $\mathrm{Ti}$ is not the preferred site for ammonia adsorption in the bimetallic system. We also demonstrated that the electron density of protonated oxygen atoms is lower than other framework oxygen atoms, ${ }^{14}$ which leads to a weaker bond with the metal site. On binding to ammonia the Ti(IV) site also adopts a trigonal bipyramidal coordination, however the protonated oxygen is forced to become axial, further weakening the $\mathrm{Ti}-\mathrm{OH}$ bond and making the coordination far less favorable. Given the minimal change in spin of the framework oxygens and the cobalt on binding to ammonia it is believed that the geometric effects are the main reason behind the difference in binding energies in the monometallic and bimetallic systems.

To become 'active' cobalt-containing AlPOs must be calcined so cobalt reaches the trivalent oxidation state required to initiate oxidation reactions. ${ }^{35}$ The role that Ti(IV) substituted AIPOs play

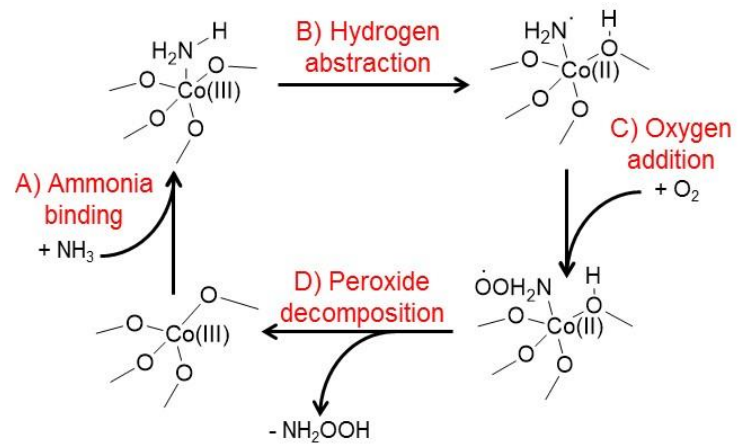

Scheme 1 Proposed reaction mechanism for the activation of ammonia showing 4 key steps: A) Ammonia binding, B) Hydrogen abstraction, C) Oxygen addition and D) Peroxide decomposition. in oxidation catalysis is still unclear; however, all our calculations on reduced bimetallic CoTiAIPO-5 systems always converge to $\mathrm{Co}$ (II) and Ti(IV) and do not converge on Co(III) and $\mathrm{Ti}(\mathrm{III})$ oxidation states. It is therefore reasonable to assume that Co is the redox active metal site responsible for $\mathrm{NH}_{3}$ activation. As such we now dedicate the rest of this script to contrasting the role of the cobalt sites in the monometallic CoAIPO- 5 and bimetallic CoTiAIPO-5 species. No interaction was observed between ammonia and oxygen either in the pore, or between individual gaseous ammonia and oxygen atoms. These factors coupled with the binding energies

(Table 1) show that the initial step of this reaction involves an interaction between ammonia and a Co(III) active site. This is in agreement with previous findings on ethane oxidation catalysed by MnAIPO-5, which shows that the rate-determining step is the initial activation of the organic substrate to form a radical species. ${ }^{23,24}$ Activation of ethane by MnAlPO-5, calculated with the same settings as in the present work, requires an activation energy of $135 \mathrm{~kJ} / \mathrm{mol}$, with a reaction enthalpy of $93 \mathrm{~kJ} / \mathrm{mol} .^{23,24}$

We suggest a similar mechanism for the activation of ammonia (Scheme 1), comprising the elementary steps of adsorption, hydrogen abstraction and $\mathrm{O}_{2}$ addition resulting in the production of $\mathrm{NH}_{2} \mathrm{OO}$. radicals. ${ }^{36,37}$ We hypothesise that this intermediate follows a peroxide decomposition pathway into hydroxylamine, likely via $\mathrm{NH}_{2} \mathrm{OOH}$ (however this is not known experimentally). ${ }^{38-40}$ In this paper we focus on the initial stages of ammonia activation, the hydrogen abstraction and $\mathrm{O}_{2}$ addition steps, in order to gain an improved insight into the behavior of the mono- and bi-metallic CoTiAIPO-5 catalyst for oxidation catalysis.

Similarly to the preactivation step of alkane oxidation, ${ }^{23-25}$ the radical formation step occurs via homolytic cleavage of one $\mathrm{N}$ $\mathrm{H}$ bond on a Co(III) site, to form an amide radical (Scheme 1B) and a reduced $\mathrm{Co}$ (II) site. The energy profile of this reaction step is examined by performing a series of constrained geometry optimizations, in which a reaction coordinate (in this case the $\mathrm{O}_{\text {Framework }}-\mathrm{H}_{\text {Ammonia }}$ distance) is progressively varied from its value in the reagents (ammonia adsorbed on $\mathrm{Co}(\mathrm{III})$ ) to that in the products.

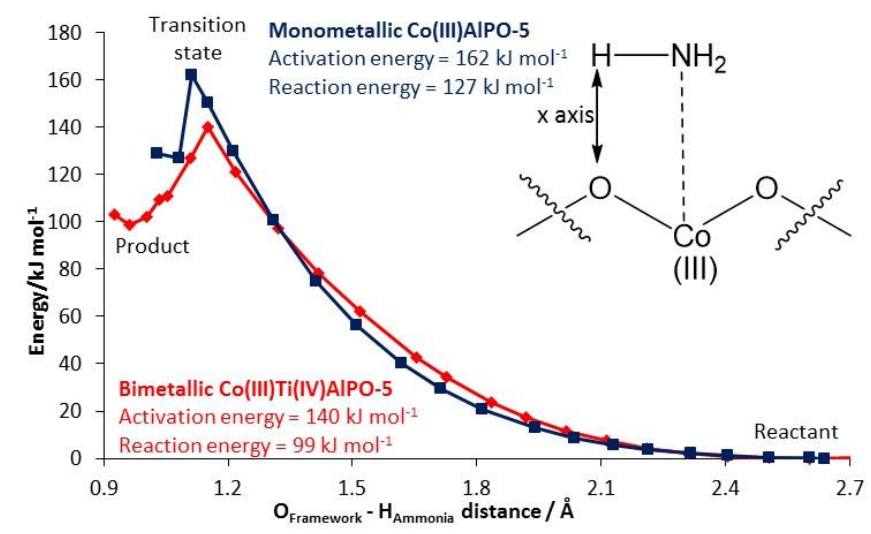

Figure 2 Internal energy profile for the ammonia activation step in monometallic Co(III)AIPO-5 and bimetallic Co(III)Ti(IV)AIPO-5. 
As the $\mathrm{O}-\mathrm{H}$ distance contracts, the $\mathrm{N}-\mathrm{H}$ bond weakens, producing the amide radical and simultaneously reducing the cobalt ion. Of the four oxygens adjacent to the cobalt ion, the specific oxygen to be protonated was chosen as the one which resulted in the lowest energy proton position in the corresponding Co(II) system. ${ }^{14}$ In the monometallic species the reaction corresponds to $\mathrm{Co}^{\prime \prime \prime}(\mathrm{OP})_{4}$ becoming $\mathrm{Co}^{\prime \prime}(\mathrm{OP})_{3}(\mathrm{OHP})$; in the bimetallic catalyst the proton binds to the oxygen of the Co$\mathrm{O}-\mathrm{Ti}$ bridge to give a $\mathrm{Co}-\mathrm{OH}-\mathrm{Ti}$ species species, i.e. from $\mathrm{Co}^{\prime \prime \prime}(\mathrm{OP})_{3}(\mathrm{OTi})$ to $\mathrm{Co}^{\prime \prime}(\mathrm{OP})_{3}(\mathrm{OHTi})$ (Tables S1-S4 and S7-S10).

The energy profiles for the radical formation step in monometallic and bimetallic systems are shown in Figure 2. The full set of $\Gamma$-point phonon modes calculated for all transition states (Figures S12-S15) discussed here are reported in the SI, to show they have the correct structure with only one imaginary mode. In both monometallic and bimetallic systems the reaction is highly endothermic, with the transition state close to the product in both activation energy and reaction coordinate. Breaking the $\mathrm{N}-\mathrm{H}$ bond in the absence of a catalyst was calculated to require $470 \mathrm{~kJ} / \mathrm{mol}$ (Figure S3), explaining the endothermic nature of the process and the need for a catalyst. Both the activation and reaction energies are lower in bimetallic Co(III)Ti(IV)AIPO-5 than in the monometallic Co(III)AIPO-5 (Figure 2), while the transition state for the bimetallic system occurs at a longer $\mathrm{O}-\mathrm{H}$ distance, in accordance with the lower activation energy. The $\mathrm{O}-\mathrm{H}$ distance of the product is significantly shorter in the bimetallic system than in the monometallic. This is attributed to a different coordination of the amide radical to the $\mathrm{Co}$ (II) site, as discussed below. The energy values calculated here are higher but comparable to those calculated for the activation of ethane with MnAIPO-5, of 135 and $93 \mathrm{~kJ} / \mathrm{mol}{ }^{23,24}$ This is a result of the different bond dissociation energies for ammonia and ethane (470 and 410 $\mathrm{kJ} / \mathrm{mol}$ respectively), thus cleavage of the stronger $\mathrm{N}-\mathrm{H}$ bond requires higher activation and reaction energies. ${ }^{41}$

Analysis of atomic distances and spin densities provides further mechanistic insights. The initial electron spin of cobalt $(3.04|\mathrm{e}|)$ is consistent with $\mathrm{Co}$ (III) (Table S4; Figures S4 and S5), and is constant up to the transition state. While tetrahedral high-spin Co(III) is expected to have 4 unpaired electrons, it is noted that the system is not perfectly tetrahedral and spin-leaching occurs onto the neighbouring oxygen atoms. On reaching the transition state $(\mathrm{O}-\mathrm{H}$ distance $1.11 \AA$ monometallic, $1.15 \AA$ bimetallic) the cobalt spin is lowered to roughly $2.7|\mathrm{e}|$, consistent with an homolytic mechanism and the reduction of $\mathrm{Co}(\mathrm{III})$ to $\mathrm{Co}$ (II) (Figures S4 and S5). ${ }^{14}$ We have already discussed in ref. 14 that the redox potential of $\mathrm{Co}$ (III) is influenced by the presence of adjacent titanium ions. ${ }^{14}$ Reduction of cobalt from Co(III) to Co(II) alleviates the build-up of electron spin of the specific (protonated) framework oxygen in the bimetallic CoTiAIPO-5 system more than in the monometallic. In the ammonia activation reaction step the oxygen spin evolution follows similar behaviour.

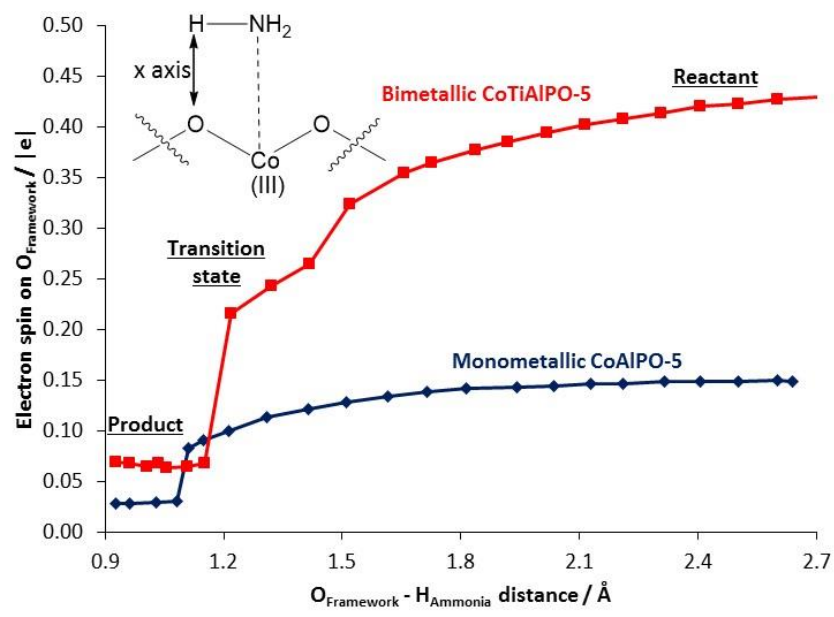

Figure 3 Comparison of the spin evolution on the framework oxygen in the monometallic and bimetallic systems.

The spin polarization of the specific framework oxygen in the bimetallic system is reduced from $0.43|\mathrm{e}|$ to $0.07|\mathrm{e}|$ (Figure 3) on protonation, whereas the spin polarization of the same specific framework oxygen in the monometallic CoAlPO-5 system reduces from $0.15|\mathrm{e}|$ to $0.03|\mathrm{e}|$ (Figure 3 ). The greater alleviation of spin on the oxygen makes this step less endothermic for the bimetallic system than the monometallic. We also suggest that the greater spin polarization on the bridging oxygen makes it more active for the activation of homolytic bond dissociations.

Comparing changes in the $\mathrm{N}-\mathrm{H}$ and $\mathrm{Co}-\mathrm{N}$ distances of the two systems reveals fundamental differences. In the monometallic CoAlPO-5 system (Figure S6) the amide radical, once formed, moves away from the cobalt ion (the Co- $\mathrm{N}$ distance elongates from $2.21 \AA$ to $3.22 \AA$, Figure S6), but retains an interaction with the hydrogen atom abstracted, resulting in a shorter $\mathrm{N}-\mathrm{H}$ distance $(1.72 \AA)$. The cobalt adopts a distorted tetrahedral geometry. Interaction with the amide radical results in a particularly long equilibrium $\mathrm{O}-\mathrm{H}$ distance of $1.08 \AA$ A. In contrast, for the bimetallic CoTiAIPO-5 system, the Co- $\mathrm{N}$ distance remains roughly constant throughout the reaction step (from $2.19 \AA$ to $2.00 \AA$, Figure S7), and an elongation of the $\mathrm{N}-\mathrm{H}$ distance occurs (from $1.02 \AA$ to $2.66 \AA$, Figure S7). The $\mathrm{O}-\mathrm{H}$ distance is not affected by interaction with the amide radical, and is measured as $0.96 \AA$. Co retains the trigonal bipyramidal geometry. This behaviour is due to the enhanced stability and bond strength of the framework oxygen-proton bond in the bimetallic system. ${ }^{14}$ The stronger interaction between the framework oxygen and the proton weakens the proton-amide interaction, and in turn promotes the Co-amide interaction. By retaining a strong interaction with the amide radical, the cobalt in the bimetallic system contributes to delocalize the spin of the molecule; the spin density of the nitrogen atom is of $0.92|\mathrm{e}|$ in the bimetallic system, compared to $1.07|\mathrm{e}|$ in the monometallic system (Figures S4 and S5). 


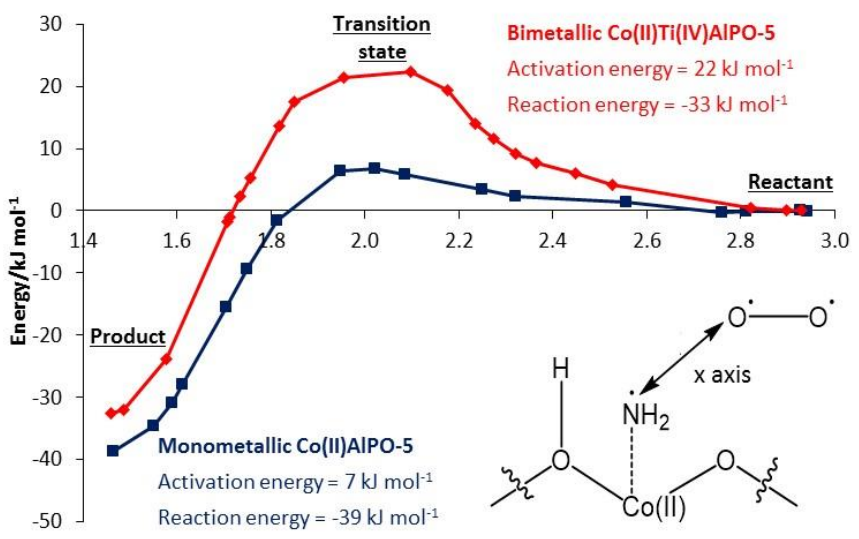

$\mathrm{N}_{\text {Ammonia }}-\mathrm{O}_{\text {Oxygen }}$ Distance / $\AA$

Figure 4 Contrasting the energy profile of $\mathrm{NH}_{2} \mathrm{OO}$ formation for monometallic Co(II)AIPO-5 and bimetallic Co(II)Ti(IV)AIPO-5.

These findings suggest that the lower reaction and activation energies for the bimetallic CoTiAIPO- 5 system, in this reaction step, are due to increased stability of the Co(II), and the increased spin stabilization of the bimetallic framework oxygen and the amide intermediate. ${ }^{14}$

Once generated, the amide radical intermediate is stabilised by addition of triplet oxygen (Scheme 1C, Figure 4), as was the case for alkyl radicals in hydrocarbon oxidation reactions. ${ }^{23,24}$ Calculations of the energy profile as a function of the $\mathrm{N}_{\text {Ammonia- }}$ $\mathrm{O}_{\text {oxygen }}$ distance (Scheme $1 \mathrm{C}$ ) shows that addition of oxygen is exothermic and requires a significantly lower activation energy than the radical formation step in both systems. Both activation and reaction energy of the oxygen addition step are lower for CoAIPO-5 than CoTiAIPO-5 (Figures 2 and 4). This is attributed to the Co-N interaction discussed earlier. While in the monometallic system the amide is only loosely bound to Co (the Co-N equilibrium bond distance is of $3.28 \AA$, Figure S6 and S8), it is strongly adsorbed in the bimetallic system ( $2.00 \AA$, Figure $\mathrm{S} 7$ and S9). The Co- $\mathrm{N}$ distance is constant in the radical stabilisation step for the monometallic system, as the bond is already broken (Figure S8).

In the bimetallic system the Co- $\mathrm{N}$ distance extends as the $\mathrm{NH}_{2} \mathrm{OO} \bullet$ radical forms, as required to break the Co- $\mathrm{N}$ bond (expanding from 2.00 to $2.83 \AA$, Figure S9) accounting for the increased activation and reaction energies of the bimetallic system. The calculated energy profiles are different to those for the analogous radical stabilization step for ethane and MnAIPO5 , which show no activation barrier and are heavily stabilized by $-149 \mathrm{~kJ} / \mathrm{mol}^{23,24}$ In contrast the monometallic and bimetallic systems calculated here show an activation barrier of 7 and 22 $\mathrm{kJ} / \mathrm{mol}$ respectively, and are stabilized to a lesser extent of -39 and $-33 \mathrm{~kJ} / \mathrm{mol}$ respectively. The difference is due to the weaker $\mathrm{N}-\mathrm{O}$ bond formed here relative to the $\mathrm{C}-\mathrm{O}$ bond in the ethane oxidation. ${ }^{42,43}$ Comparison of the mechanisms shows that the monometallic system behaves in an analogous way to the MnAIPO- 5 system. Both break the metal-radical bond (Co-N and $\mathrm{Mn}-\mathrm{C}$ ) in the radical formation step, as the radical maintains an interaction with the abstracted proton.

The electron spins of the two systems (Figure S10 and S11), provide some mechanistic insight.

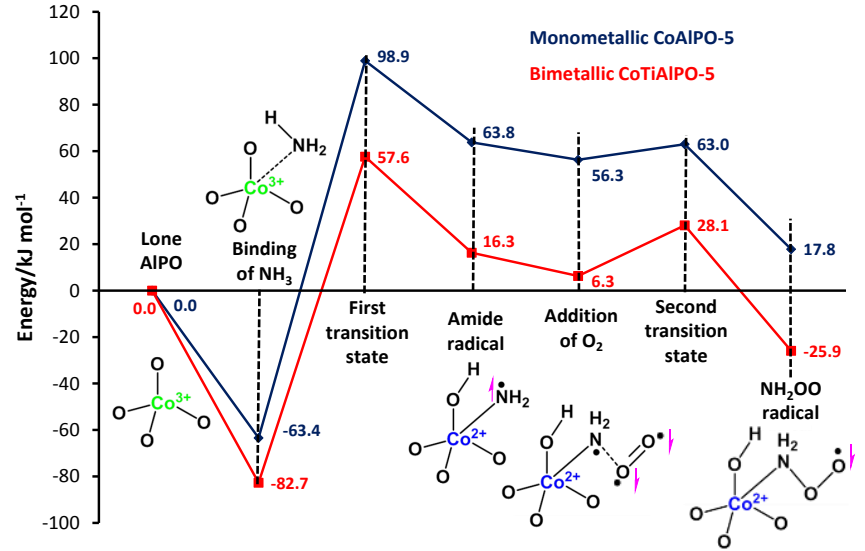

Figure 5 Complete energetic profile of the two reaction steps examined, in mono and bimetallic catalysts.

As oxygen approaches the amide radical, a covalent bond forms involving the $\alpha$ electron of the amide and a $\beta$ electron on the oxygen (01). This is seen by the short $\mathrm{N}-\mathrm{O}$ bond length of the product (1.46 ̊̊ for both monometallic and bimetallic) and also by the total spin decreasing by roughly $2|\mathrm{e}|$ in both systems. Only very slight differences were observed in the cobalt and nitrogen spins between the two systems (Figures S10 and S11), despite the difference in bond lengths. This suggests that the strength of the amide stabilisation by complexation of $\mathrm{Co}(\mathrm{II})$ is the primary factor in the energy difference between mono- and bi-metallic catalysts in the radical stabilization step.

The energetic profile of the two steps discussed here is shown in Figure 5. The rate determining step is the hydrogen abstraction from $\mathrm{NH}_{3}$, leading the radical formation, in accordance with previous work. ${ }^{14,23,24}$ The lower activation energy calculated for this step in the bimetallic system over the monometallic provides mechanistic detail concerning the benefits of bimetallic substitution.

\section{Dispersion corrections and free energy}

The energy values discussed in section 1 refer to internal energies from the original B3LYP DFT calculations. This functional does not account for dispersion forces, that we have estimated using the empirical D2 correction proposed by Grimme. ${ }^{32}$ We have also estimated the vibrational contribution to free energy (zero point energy and vibrational entropy) at room temperature for reagents, products and transition states using the geometries identified in section 1 .

Results for the $\mathrm{NH}_{3}$ activation and $\mathrm{O}_{2}$ addition steps in both mono and bi-metallic catalysts are summarized in Table 3 . While dispersion increases, as expected, the adsorption energies of $\mathrm{NH}_{3}$ and $\mathrm{O}_{2}$ molecules on the active sites, it has smaller effect on reaction and activation energies (Figure S16).

$\mathrm{NH}_{3}$ activation comprises a $\mathrm{H}$-transfer step with minor changes of bond distances other than those involving the $\mathrm{N}$ and $\mathrm{H}$ atoms of the bond being cleaved, while $\mathrm{O}_{2}$ addition too requires 
Table 3 Summary of calculated activation and reaction energies $(\mathrm{kJ} / \mathrm{mol})$ for $\mathrm{NH}_{3}$ activation and $\mathrm{O}_{2}$ addition steps in mono and bi-metallic catalysts, including dispersion and entropic contributions.

\begin{tabular}{|c|c|c|c|c|c|}
\hline \multicolumn{2}{|c|}{ Monometallic reaction step } & \multicolumn{4}{|c|}{ Reaction energies/(kJ mol $\left.{ }^{-1}\right)$} \\
\hline & & Electronic energy & $\begin{array}{c}\text { Electronic energy + } \\
\text { dispersion }\end{array}$ & Free energy & $\begin{array}{c}\text { Free energy + } \\
\text { dispersion }\end{array}$ \\
\hline Step A. Ammonia binding & $\Delta \mathrm{E}_{\mathrm{NH}_{3}}{ }^{\text {ads }}$ & -63.4 & -100.8 & -41.7 & -77.7 \\
\hline \multirow[t]{2}{*}{ Step B. Hydrogen abstraction } & $E_{a}^{B}$ & 162.3 & 185.3 & 151.7 & 174.6 \\
\hline & $\Delta \mathrm{E}^{\mathrm{B}}$ & 127.2 & 148.1 & 111.4 & 133.2 \\
\hline \multirow[t]{2}{*}{ Step C. Oxygen addition } & $\Delta \mathrm{EO}_{2}{ }^{\text {ads }}$ & -7.5 & -26 & 6.7 & -12.4 \\
\hline & $\Delta \mathrm{E}^{\mathrm{C}}$ & -38.5 & -43.9 & -33.1 & -32.2 \\
\hline \multicolumn{2}{|c|}{ Bimetallic reaction step } & \multicolumn{4}{|c|}{ Reaction energies/(kJ mol $\left.{ }^{-1}\right)$} \\
\hline & & Electronic energy & $\begin{array}{c}\text { Electronic energy + } \\
\text { dispersion }\end{array}$ & Free energy & $\begin{array}{c}\text { Free energy + } \\
\text { dispersion }\end{array}$ \\
\hline Step A. Ammonia binding & $\Delta \mathrm{E}_{\mathrm{NH}_{3}}{ }^{\text {ads }}$ & -82.7 & -97.2 & -56.1 & -70.6 \\
\hline \multirow[t]{2}{*}{ Step B. Hydrogen abstraction } & $E_{a}^{B}$ & 138.9 & 128.6 & 121.5 & 111.1 \\
\hline & $\Delta \mathrm{E}^{\mathrm{B}}$ & 98.0 & 87.7 & 84.6 & 74.4 \\
\hline \multirow{2}{*}{ Step C. Oxygen addition } & $E_{a}^{c}$ & 21.6 & 20.9 & 20.7 & 20.1 \\
\hline & $\Delta \mathrm{E}^{\mathrm{C}}$ & -53.6 & -46.0 & -46.7 & -39.1 \\
\hline
\end{tabular}

relatively small atomic displacements (the $\mathrm{N}$-based radical is oriented away from the framework) that cause small changes in dispersion. Dispersion however enhances the overall difference between the activation energy for $\mathrm{NH}_{3}$ activation in mono and bimetallic catalysts, due to the different coordination geometry of the $\cdot \mathrm{NH}_{2}$ radical in the two cases, as discussed in section 1 . Vibrational contributions to the free energy also have relatively small effects (of less than $15 \mathrm{~kJ} / \mathrm{mol}$, Figure S17) on reaction and activation energies of both reaction steps. Despite $\mathrm{O}_{2}$ addition causing a decrease in the number of molecules, because $\mathrm{O}_{2}$ prior to the reaction is not rotationally and translationally free but confined in the AIPO-5 pores and weakly interacting with the framework (rotational and translational modes of $\mathrm{O}_{2}$ correspond to frequencies ranging between 40 and $150 \mathrm{~cm}^{-1}$ ), its loss in translational and rotational entropy is substantially smaller than in the equivalent gas-phase reaction. Despite the actual reaction and activation energies show some dependence on whether and how dispersion and entropic contributions are included (Figure S18), the overall picture of the reaction mechanism is unchanged, with the $\mathrm{NH}_{3}$ activation being the rate determining step, and the bimetallic catalyst showing much enhanced activity over the monometallic for this reaction step.

\section{Conclusions}

By employing periodic DFT calculations we have shown the benefits of bimetallic substitution in microporous AIPO catalysts. Through careful investigation of the initial reaction steps of the aerobic activation of ammonia we have revealed that the activation energy of the rate determining radical formation step can be lowered through the application of a bimetallic CoTiAIPO-5 catalyst, enhancing catalytic activity over the monometallic CoAIPO-5 catalyst. Ti does not directly take part in the catalytic reaction, but its presence in a framework site adjacent to Co modifies substantially the adsorption energy of ammonia, and the $\mathrm{Co}(\mathrm{III}) / \mathrm{Co}$ (II) reduction potential, stabilising the $2+$ oxidation state and hence all those elementary reaction steps that occur through reduction of $\mathrm{Co}(\mathrm{III})$. These include the radical $\mathrm{H}$ abstraction from $\mathrm{NH}_{3}$ that initiates (and is the limiting step for) the in situ production of hydroxylamine. The bridging framework oxygen between $\mathrm{Co}$ and $\mathrm{Ti}$ has a prominent role in the synergic enhancement of catalytic activity. Its location between one electron rich (Co(III), $\mathrm{d}^{6}$ ) and one electron poor ( $\left.\mathrm{Ti}(\mathrm{IV}), \mathrm{d}^{0}\right)$ transition metal ion contributes to the delocalisation of the $\mathrm{Co}$ (III) spin density. In the bare CoTiAIPO- 5 catalyst, the bridging oxygen has a noticeable spin polarisation of $0.419|\mathrm{e}|$ that activates its reactivity in elementary steps that require radical formation.

We have shown that design strategies aimed at developing improved catalysts for ammonia activation should be targeted at minimizing the activation barrier for the radical formation step. The lower activation energy calculated for the bimetallic system over the monometallic shows the enhanced activity and provides an atomistic explanation for the bimetallic synergy observed experimentally.

\section{Acknowledgements}

MEP and RR gratefully acknowledge Honeywell LLC for funding. Archer access (http://www.archer.ac.uk) was granted through membership of the UK's HEC Materials Chemistry Consortium, funded by EPSRC (EP/L000202).

\section{References}

1 R. Raja, M. E. Potter and S. H. Newland, Chem. Commun., 2014, 50, 5940-5957.

2 R. D. Oldroyd, J. M. Thomas and G. Sankar, Chem. Commun., 1997, 21, 2025-2056. 
3 L. Kesavan, R. Tiruvalam, M. H. Ab Rahim, M. I. bin Saiman, D. I.; Enache, R. L. Jenkins, N. Dimitratos, J. A. Lopez-Sanchez, S H. Taylor, D. W. Knight, C. J. Kiely and G. J. Hutchings, Science, 2011, 331, 195-199.

4 M. R. Morrill, N. T. Thao, H. Shou, R. J. Davis, D. G. Barton, D. Ferrari, P. K. Agrawal and C. W. Jones, ACS Catal., 2013, 3, 1665-1675.

5 D. Zhang, Y. Wei, L. Xu, F. Chang, Z. Liu, S. Meng, B. L. Su and Z. Liu, Micropor. Mesopor. Mater., 2008, 116, 684-692.

6 R. D. Adams, B. Captain, W. Fu, M. B. Hall, J. Manson, M. D. Smith and C. E. Webster, J. Am. Chem. Soc., 2004, 126, 52535267.

7 S. Fietcher, I. Dorbandt, P. Bogdanoff, G. Zehl, H. Schulenburg, H. Tributsch, M. Bron, J. Radnik and M. Fieber-Erdmann, J. Phys. Chem. C, 2007, 111, 477-487.

8 D. M. Alonso, S. G. Wettstein and J. A. Dumesic, Chem. Soc. Rev., 2012, 41, 8075-8098.

9 P. Visuvamithiran, K. Shanthi, M. Palanichamy and V. Murugesan, Catal. Sci. Technol., 2013, 3, 2340-2348.

10 R. M. Leithall, V. N. Shetti, S. Maurelli, M. Chiesa, E. Gianotti and R. Raja, J. Am. Chem. Soc., 2013, 135, 2915-2918.

11 L. Zhou, J. U. H. Miao, X. Li and F. Wang, Catal. Lett., 2005, 99, 231-234.

12 E. Gianotti, M. Manzoli, M. E. Potter, V. N. Shetti, D. Sun, A. J. Paterson, T. M. Mezza, A. Levy and R. Raja, Chem. Sci., 2014, 5, 1810-1819.

13 J. Paterson, M. E. Potter, E. Gianotti and R. Raja, Chem Commun., 2011, 47, 517-519.

14 M. E. Potter, A. J. Paterson, B. Mishra, S. D. Kelly, S. R. Bare, F. Cora', A. B. Levy and R. Raja, J. Am. Chem. Soc., 2015, 137 8534-8540.

15 M. G. Clerici, G. Bellussi and U. Romano, J. Catal., 1991, 129 159-167.

16 P. E. Sinclair, G. Sankar, C. R. A. Catlow, J. M. Thomas and T. Maschmeyer, J. Phys. Chem. B, 1997, 101, 4232-4237.

17 I. Saadoune, F. Cora', M. Alfredsson and C. R. A. Catlow, J. Phys. Chem. B, 2003, 107, 3012-3018.

18 R. Raja, US Patent, 2010, US2010/0179317 A1.

19 J. M. Thomas and R. Raja, Proc. Natl. Acad. Sci. U. S. A., 2005, 102, 13732-13736.

20 F. Cora', M. Alfredsson, C. M. Barker, R. G. Bell, M. D. Foster, I. Saadoune, A. Simplerer and C. R. A. Catlow, J. Solid State Chem., 2003, 176, 496-529.

21 C. M. Barker, D. Gleeson, N. Kaltsoyannis, C. R. A. Catlow, G. Sankar and J. M. Thomas, Phys. Chem. Chem. Phys., 2002, 4 1228-1240.

22 E. L. Uzunova, H. Mikosch and J. Hafner, J. Phys. Chem. C, 2008, 112, 2632-2639.

23 L. Gomez-Hortiguela, F. Cora', G. Sankar, C. M. ZicovichWilson and C. R. A. Catlow, Chem. - Eur. J., 2010, 16, 1363813645.

24 L. Gomez-Hortiguela, F. Cora' and C. R. A. Catlow, ACS. Catal. 2011, 1, 18-28.

25 L. Gomez-Hortiguela, F. Cora' and C. R. A. Catlow, Phys. Chem. Chem. Phys., 2013, 15, 6870-6874.

26 R. Dovesi, R. Orlando, B. Civalleri, C. Roetti, V. R. Saunders and C. M. Zicovich-Wilson, Z. Kristallogr., 2005, 220, 571-573.

27 A. D. Becke, J Chem. Phys., 1993, 98, 5648-5652.

28 C. Lee, W. Yang and R. G. Parr, Phys. Rev. B, 1988, 37, 785-789.

29 S. H. Vosko, L. Willk and M. Nusair, Can. J. Phys., 1980, 58 1200-1211.

30 P. J. Stephens, F. J. Devlin, C. F. Chabalowski and M. J. Frisch, J. Phys. Chem., 1994, 98, 11623-11627.

31 CRYSTAL Basis Sets Library. (http://www.crystal.unito.it/Basis_Sets/Ptable.html) accessed July 2016.

32 S. Grimme, J. Comp. Chem., 2006, 27, 1787-1799.
33 L. Gomez-Hortiguela, F. Cora', C. R. A. Catlow and J. PerezPariente, J. Am. Chem. Soc., 2004, 126, 12097-12102.

34 C. Glidewell, J. Coord. Chem., 1977, 6, 189-192.

35 P. A. Barrett, G. Sankar, C. R. A. Catlow and J. M. Thomas, J. Phys. Chem., 1996, 100, 8977-8985.

36 R. Sumathi and S. D. A. Peyerimhoff, Chem. Phys. Lett., 1996, 263, 742-748.

37 A. Samuni, S. Goldstein, A. Russo, J. B. Mithcell, M. C. Krishna and P. Neta, J. Am. Chem. Soc., 2002, 124, 8719-8724.

38 L. Gomez-Hortiguela, F. Cora' and C. R. A. Catlow, ACS. Catal., 2011, 1, 945-955.

39 L. Gomez-Hortiguela, F. Cora' and C. R. A. Catlow, ACS Catal., 2011, 1, 1487-1497.

40 L. Gomez-Hortiguela, F. Cora and C. R. A. Catlow, ACS Catal., 2011, 1, 1475-1486.

41 B. S. Jursic, J. Chem. Soc., Perkin Trans. 2, 1999, 2, 369-372.

42 G. Glockler, J. Phys. Chem., 1958, 62, 1049-1054.

43 G. Glockler, J. Chem. Phys., 1951, 19, 124-125. 


\title{
SUPPLEMENTARY INFORMATION
}

Theoretical insights into the nature of synergistic enhancement in bimetallic CoTiAIPO-5 catalysts for ammonia activation

\author{
Matthew E. Potter, ${ }^{a *}$ Kit McColl, ${ }^{b}$ Furio Corà, ${ }^{b}$ Alan B. Levyc and Robert Raja ${ }^{a}$ \\ a Department of Chemistry, University of Southampton, Department of Chemistry, University Road, \\ Southampton, Hants, SO17 1BJ, UK. \\ ${ }^{\mathrm{b}}$ Department of Chemistry, University College London, 20 Gordon Street, London, WC1H 0AJ, UK. \\ c Honeywell Int, 101 Columbia Road, Morristown, NJ 07962, USA.
}

\section{Contents}

Calculated equilibrium geometries of mono- and bi-metallic catalysts

Page S2

Calculated equilibrium geometries of bound monometallic catalysts

Page S4

Calculated equilibrium geometries of bound bimetallic catalysts

Page S7

DFT calculated $\mathrm{NH}_{3}$ coordination geometries

Page $\mathrm{S} 8$

Non catalytic $\mathrm{N}-\mathrm{H}$ activation energy profile

Page 59

Hydrogen abstraction step

Page S10

Evolution of spin

Page S10

Evolution of bond lengths

Page S11

Oxygen addition step

Page S12

Evolution of bond lengths

Page S12

Evolution of spin

Page S13

Transition state vibrational frequency calculations

Page S14

Monometallic hydrogen abstraction transition state

Page S14

Bimetallic hydrogen abstraction transition state

Page S15

Monometallic oxygen addition transition state

Page S16

Bimetallic oxygen addition transition state

Page S17

Transition state figures

Page S19

Complete energetics

Page S21

Electronic energy + dispersion

Page S21

Free energy

Page S21

Free energy + dispersion 
Calculated equilibrium geometries of mono- and bi-metallic catalysts

Monometallic Co(II)AIPO-5

Table S1: Bond lengths in monometallic Co(II)AIPO-5.

\begin{tabular}{|l|l|l|}
\hline Atom 1 & Atom 2 & Bond length/Å \\
\hline Co1 & $\mathrm{O} 1(\mathrm{H} 1)$ & 2.120 \\
\hline $\mathrm{Co} 1$ & $\mathrm{O} 2$ & 1.871 \\
\hline $\mathrm{Co} 1$ & $\mathrm{O} 3$ & 1.897 \\
\hline Co1 & $\mathrm{O} 4$ & 1.876 \\
\hline & & \\
\hline $\mathrm{O} 1(\mathrm{H} 1)$ & $\mathrm{P} 1(\mathrm{H} 1)$ & 1.608 \\
\hline $\mathrm{O} 2$ & $\mathrm{P} 2$ & 1.518 \\
\hline $\mathrm{O} 3$ & $\mathrm{P} 3$ & 1.520 \\
\hline $\mathrm{O} 4$ & $\mathrm{P} 4$ & 1.524 \\
\hline & & \\
\hline $\mathrm{O} 1$ & $\mathrm{H} 1$ & 0.992 \\
\hline
\end{tabular}

Monometallic Co(III)AIPO-5

Table S2: Bond lengths in monometallic Co(III)AIPO-5.

\begin{tabular}{|c|c|c|}
\hline Atom 1 & Atom 2 & Bond length/Å \\
\hline Co1 & 01 & 1.816 \\
\hline Co1 & $\mathrm{O} 2$ & 1.820 \\
\hline Co1 & $\mathrm{O3}$ & 1.837 \\
\hline Co1 & O4 & 1.822 \\
\hline $\mathrm{O} 1$ & P1 & 1.548 \\
\hline $\mathrm{O} 2$ & P2 & 1.545 \\
\hline $\mathrm{O3}$ & P3 & 1.541 \\
\hline 04 & P4 & 1.546 \\
\hline
\end{tabular}

Monometallic Ti(IV)AIPO-5

Table S3: Bond lengths in monometallic Ti(IV)AIPO-5.

\begin{tabular}{|c|c|c|}
\hline Atom 1 & Atom 2 & Bond length/Å \\
\hline Ti1 & $\mathrm{O} 1(\mathrm{H} 1)$ & 1.987 \\
\hline Ti1 & $\mathrm{O} 2$ & 1.775 \\
\hline Ti1 & O3 & 1.765 \\
\hline Ti1 & $\mathrm{O} 4$ & 1.751 \\
\hline $\mathrm{O} 1(\mathrm{H} 1)$ & Al1 (H1) & 1.792 \\
\hline $\mathrm{O} 2$ & $\mathrm{Al} 2$ & 1.700 \\
\hline 03 & $\mathrm{Al} 3$ & 1.711 \\
\hline 04 & Al4 & 1.751 \\
\hline 01 & $\mathrm{H} 1$ & 0.970 \\
\hline
\end{tabular}




\section{Bimetallic Co(II)Ti(IV)AIPO-5}

Table S4: Bond lengths in bimetallic Co(II)Ti(IV)AIPO-5.

\begin{tabular}{|l|l|l|}
\hline Atom 1 & Atom 2 & Bond length/Å \\
\hline Co1 & O1 (H1) (Bridge) & 1.973 \\
\hline Co1 & $\mathrm{O} 2$ & 1.909 \\
\hline Co1 & $\mathrm{O} 3$ & 1.782 \\
\hline Co1 & $\mathrm{O} 4$ & 2.005 \\
\hline Ti1 & $\mathrm{O} 1(\mathrm{H} 1)$ (Bridge) & 1.961 \\
\hline Ti1 & $\mathrm{O} 5(\mathrm{H} 2)$ & 1.983 \\
\hline Ti1 & $\mathrm{O} 6$ & 1.731 \\
\hline Ti1 & $\mathrm{O} 7$ & 1.719 \\
\hline & & \\
\hline $\mathrm{O} 2$ & $\mathrm{P} 1$ & 1.514 \\
\hline $\mathrm{O} 3$ & $\mathrm{P} 2$ & 1.519 \\
\hline $\mathrm{O} 4$ & $\mathrm{P} 3$ & 1.540 \\
\hline $\mathrm{O} 5(\mathrm{H} 2)$ & $\mathrm{Al} 1(\mathrm{H} 2)$ & 1.801 \\
\hline $\mathrm{O} 6$ & $\mathrm{Al} 2$ & 1.703 \\
\hline $\mathrm{O} 7$ & $\mathrm{Al}$ & 1.731 \\
\hline & & \\
\hline $\mathrm{O} 1(\mathrm{H} 1)$ (Bridge) & $\mathrm{H} 1$ & 0.973 \\
\hline $\mathrm{O} 5(\mathrm{H} 2)$ & $\mathrm{H} 2$ & 0.982 \\
\hline
\end{tabular}

\section{Bimetallic Co(III)Ti(IV)AIPO-5}

Table S5: Bond lengths in bimetallic Co(III)Ti(IV)AIPO-5.

\begin{tabular}{|l|l|l|}
\hline Atom 1 & Atom 2 & Bond length/A \\
\hline Co1 & O1 (Bridge) & 1.757 \\
\hline Co1 & O2 & 1.860 \\
\hline Co1 & O3 & 1.743 \\
\hline Co1 & O4 & 1.931 \\
\hline Ti1 & O1 (Bridge) & 1.928 \\
\hline Ti1 & O5 (H1) & 1.988 \\
\hline Ti1 & O6 & 1.744 \\
\hline Ti1 & O7 & 1.768 \\
\hline & & \\
\hline O2 & P1 & 1.534 \\
\hline O3 & P2 & 1.534 \\
\hline O4 & P3 & 1.557 \\
\hline O5 (H1) & Al1 (H1) & 1.805 \\
\hline O6 & Al2 & 1.665 \\
\hline O7 & Al3 & 1.726 \\
\hline & & \\
\hline O5 (H1) & H1 & 0.975 \\
\hline & & \\
\hline
\end{tabular}




\section{Calculated equilibrium geometries of bound monometallic catalysts}

Table S6: Bond lengths in monometallic Co(II)AIPO-5 bound to $\mathrm{O}_{2}$.

\begin{tabular}{|c|c|c|}
\hline Atom 1 & Atom 2 & Bond length/Å \\
\hline Co1 & $\mathrm{O} 1(\mathrm{H})$ & 2.120 \\
\hline Co1 & $\mathrm{O} 2$ & 1.881 \\
\hline Co1 & $\mathrm{O3}$ & 1.900 \\
\hline Co1 & 04 & 1.876 \\
\hline $\mathrm{O} 1(\mathrm{H})$ & P1 (H) & 1.608 \\
\hline $\mathrm{O} 2$ & $\mathrm{P} 2$ & 1.517 \\
\hline 03 & P3 & 1.519 \\
\hline 04 & P4 & 1.518 \\
\hline $\mathrm{O} 1(\mathrm{H})$ & $\mathrm{H} 1$ & 0.992 \\
\hline Co1 & 05 & 3.215 \\
\hline Co1 & 06 & 4.135 \\
\hline 05 & 06 & 1.227 \\
\hline
\end{tabular}

Table S7: Bond lengths in monometallic $\mathrm{Co}(\mathrm{III}) \mathrm{AIPO}-5$ bound to $\mathrm{O}_{2}$.

\begin{tabular}{|c|c|c|}
\hline Atom 1 & Atom 2 & Bond length/Å \\
\hline Co1 & 01 & 1.838 \\
\hline Co1 & $\mathrm{O} 2$ & 1.826 \\
\hline Co1 & $\mathrm{O3}$ & 1.835 \\
\hline Co1 & $\mathrm{O} 4$ & 1.819 \\
\hline 01 & P1 & 1.541 \\
\hline $\mathrm{O} 2$ & $\mathrm{P} 2$ & 1.548 \\
\hline $\mathrm{O3}$ & P3 & 1.540 \\
\hline 04 & P4 & 1.545 \\
\hline Co1 & 05 & 3.423 \\
\hline Co1 & 06 & 4.097 \\
\hline $\mathrm{O} 5$ & O5 & 1.227 \\
\hline
\end{tabular}

Table S8: Bond lengths in monometallic Ti(IV)AIPO-5 bond to $\mathrm{O}_{2}$.

\begin{tabular}{|c|c|c|}
\hline Atom 1 & Atom 2 & Bond length/Å \\
\hline Ti1 & $\mathrm{O} 1(\mathrm{H})$ & 1.995 \\
\hline Ti1 & $\mathrm{O} 2$ & 1.760 \\
\hline Ti1 & O3 & 1.768 \\
\hline Ti1 & $\mathrm{O} 4$ & 1.751 \\
\hline
\end{tabular}




\begin{tabular}{|l|l|l|}
\hline & & \\
\hline O1 $(\mathrm{H})$ & Al1 $(\mathrm{H})$ & 1.791 \\
\hline O2 & Al2 & 1.701 \\
\hline O3 & Al3 & 1.713 \\
\hline O4 & Al4 & 1.711 \\
\hline & & \\
\hline O1 (H) & H1 & 0.696 \\
\hline & & \\
\hline Ti1 & O5 & 3.001 \\
\hline Ti1 & O6 & 3.746 \\
\hline O5 & O5 & 1.227 \\
\hline
\end{tabular}

Table S9: Bond lengths in monometallic Co(II)AIPO-5 bound to $\mathrm{NH}_{3}$.

\begin{tabular}{|l|l|l|}
\hline Atom 1 & Atom 2 & Bond length/A \\
\hline Co1 & O1 & 1.814 \\
\hline Co1 & O2 & 1.838 \\
\hline Co1 & O3 & 1.852 \\
\hline Co1 & O4 & 1.964 \\
\hline & & \\
\hline O1 & P1 & 1.536 \\
\hline O2 & P2 & 1.535 \\
\hline O3 & P3 & 1.527 \\
\hline O4 & P4 & 1.526 \\
\hline & & \\
\hline Co1 & N1 & 2.208 \\
\hline N1 & H1 & 1.017 \\
\hline N1 & H2 & 1.017 \\
\hline N2 & H3 & 1.019 \\
\hline & & \\
\hline
\end{tabular}


Table S10: Bond lengths in monometallic Co(III)AIPO-5 bound to $\mathrm{NH}_{3}$.

\begin{tabular}{|l|l|l|}
\hline Atom 1 & Atom 2 & Bond length/Å \\
\hline Co1 & O1 $(\mathrm{H})$ & 2.136 \\
\hline Co1 & O2 & 1.953 \\
\hline Co1 & O3 & 1.981 \\
\hline Co1 & O4 & 1.923 \\
\hline & & \\
\hline O1 $(\mathrm{H})$ & P1 $(\mathrm{H})$ & 1.596 \\
\hline O2 & P2 & 1.509 \\
\hline O3 & P3 & 1.512 \\
\hline O4 & P4 & 1.508 \\
\hline & & \\
\hline O1 $(\mathrm{H})$ & H1 & 1.001 \\
\hline & & \\
\hline Co1 & N1 & 2.215 \\
\hline N1 & H2 & 1.017 \\
\hline N1 & H3 & 1.018 \\
\hline N2 & H4 & 1.018 \\
\hline
\end{tabular}

Table S11: Bond lengths in monometallic Ti(IV)AIPO-5 bound to $\mathrm{NH}_{3}$.

\begin{tabular}{|c|c|c|}
\hline Atom 1 & Atom 2 & Bond length/Å \\
\hline Ti1 & $\mathrm{O} 1(\mathrm{H})$ & 2.097 \\
\hline Ti1 & $\mathrm{O} 2$ & 1.789 \\
\hline Ti1 & O3 & 1.801 \\
\hline Ti1 & $\mathrm{O4}$ & 1.760 \\
\hline $\mathrm{O} 1(\mathrm{H})$ & Al1 $(H)$ & 1.759 \\
\hline $\mathrm{O} 2$ & $\mathrm{Al} 2$ & 1.709 \\
\hline 03 & $\mathrm{Al} 3$ & 1.690 \\
\hline 04 & Al4 & 1.704 \\
\hline $\mathrm{O} 1(\mathrm{H})$ & $\mathrm{H} 1$ & 0.968 \\
\hline Ti1 & N1 & 2.254 \\
\hline N1 & $\mathrm{H} 2$ & 1.017 \\
\hline N1 & $\mathrm{H} 3$ & 1.019 \\
\hline N2 & $\mathrm{H} 4$ & 1.021 \\
\hline
\end{tabular}




\section{Calculated equilibrium geometries of bound bimetallic catalysts}

Table S12: Bond lengths in bimetallic Co(III)Ti(IV)AIPO-5 with ammonia bound to the cobalt site.

\begin{tabular}{|l|l|l|}
\hline Atom 1 & Atom 2 & Bond length/Å \\
\hline Co1 & O1 (Bridge) & 1.733 \\
\hline Co1 & O2 & 1.862 \\
\hline Co1 & O3 & 1.887 \\
\hline Co1 & O4 & 2.122 \\
\hline Ti1 & O1 (Bridge) & 1.745 \\
\hline Ti1 & O5 & 1.747 \\
\hline Ti1 & O6 & 1.806 \\
\hline Ti1 & O7 (H1) & 1.978 \\
\hline & & \\
\hline O2 & P1 & 1.514 \\
\hline O3 & P2 & 1.543 \\
\hline O4 & P3 & 1.530 \\
\hline O5 & Al1 & 1.726 \\
\hline O6 & Al2 & 1.722 \\
\hline O7 (H1) & Al3 & 1.776 \\
\hline & & \\
\hline O7 (H1) & H1 & 0.969 \\
\hline & & \\
\hline Co1 & N1 & 2.186 \\
\hline N1 & H2 & 1.017 \\
\hline N1 & H3 & 1.018 \\
\hline N1 & H4 & 1.019 \\
\hline & & \\
\hline
\end{tabular}

Table S13: Bond lengths in bimetallic Co(III)Ti(IV)AIPO-5 with ammonia bound to the titanium site.

\begin{tabular}{|l|l|l|}
\hline Atom 1 & Atom 2 & Bond length/A \\
\hline Co1 & O1 (Bridge) & 1.726 \\
\hline Co1 & O2 & 1.844 \\
\hline Co1 & O3 & 1.871 \\
\hline Co1 & O4 & 1.873 \\
\hline Ti1 & O1 & 1.750 \\
\hline Ti1 & O5 & 1.761 \\
\hline Ti1 & O6 & 1.844 \\
\hline Ti1 & O7 (H1) & 2.008 \\
\hline & & \\
\hline O2 & P1 & 1.514 \\
\hline O3 & P2 & 1.543 \\
\hline O4 & P3 & 1.530 \\
\hline O5 & Al1 & 1.729 \\
\hline O6 & Al2 & 1.722 \\
\hline O7 (H1) & Al3 & 1.776 \\
\hline & & \\
\hline O7 (H1) & H1 & 0.969 \\
\hline & & \\
\hline Ti1 & N1 & 2.239 \\
\hline N1 & H2 & 1.019 \\
\hline N1 & H3 & 1.020 \\
\hline N1 & H4 & 1.021 \\
\hline & & \\
\hline
\end{tabular}




\section{DFT Calculated $\mathrm{NH}_{3}$ coordination geometries}

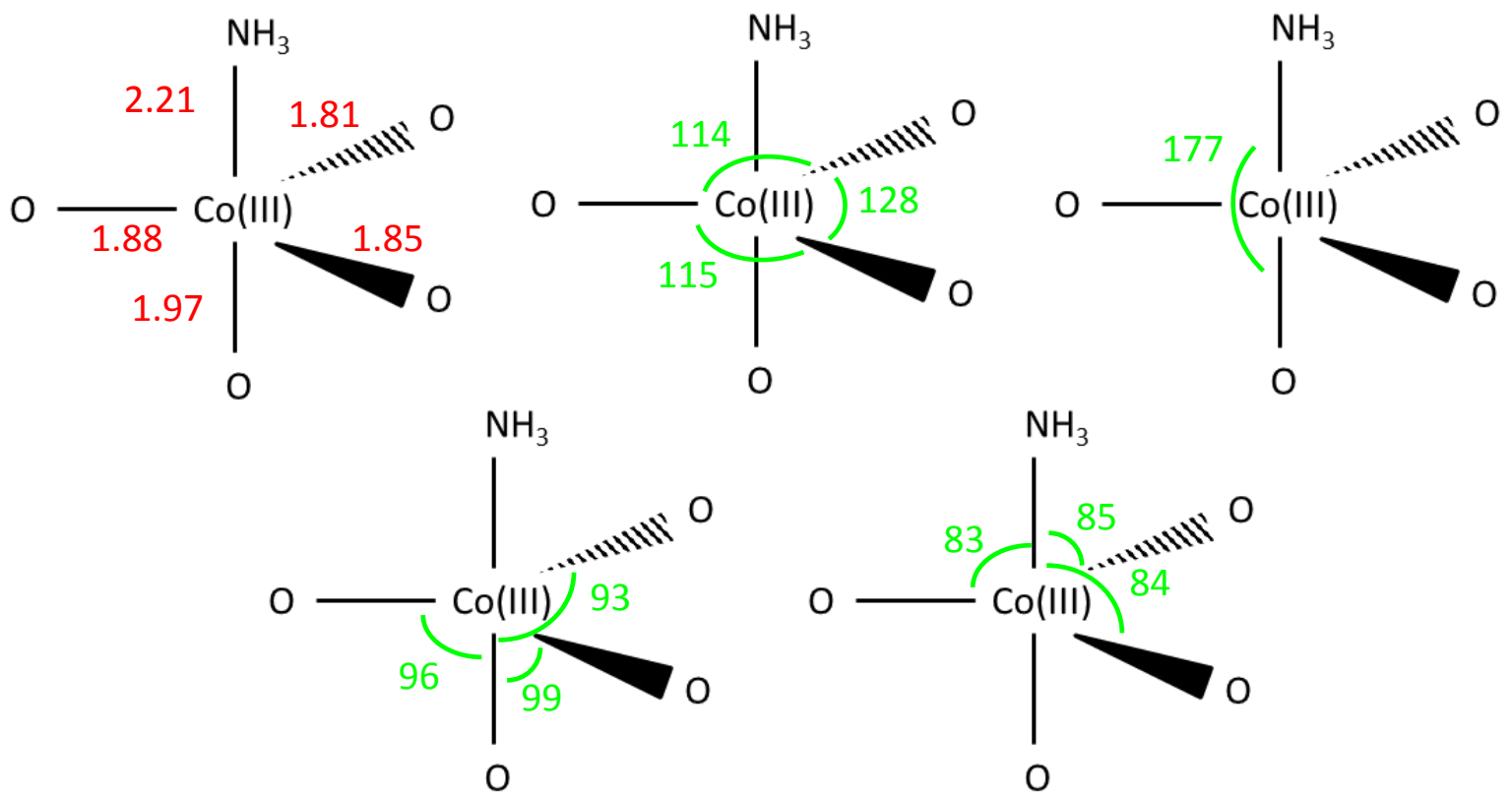

Figure S1: Geometric coordination of $\mathrm{NH}_{3}$ to monometallic $\mathrm{Co}(\mathrm{III}) \mathrm{AlPO}-5$ showing the trigonal bipyramidal shape. Red numbers represent lengths in angstroms, green values are angles in degrees.

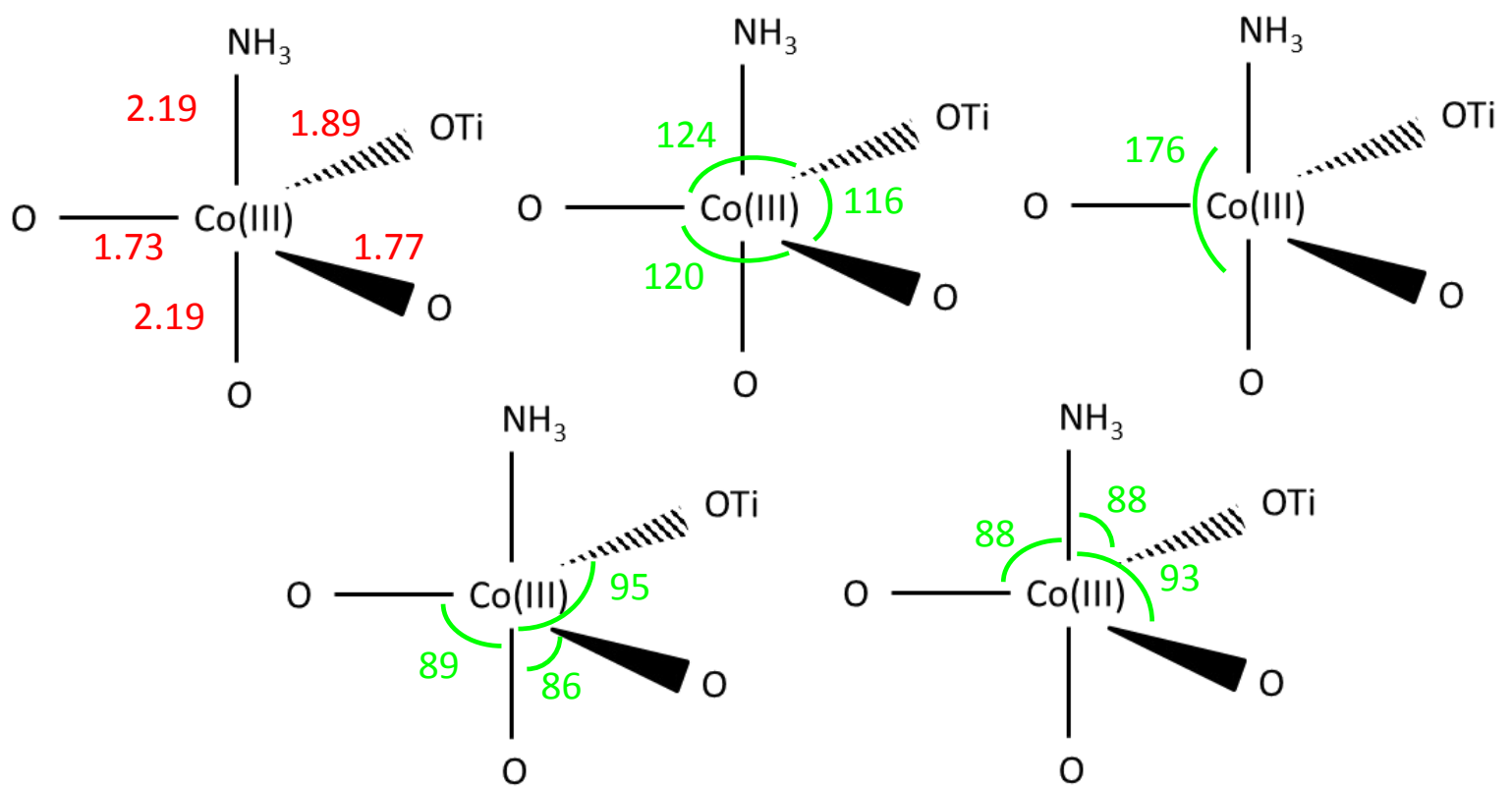

Figure S2: Geometric coordination of $\mathrm{NH}_{3}$ to bimetallic $\mathrm{Co}(\mathrm{III}) \mathrm{Ti}(\mathrm{IV}) \mathrm{AlPO}-5$ showing the trigonal bipyramidal shape. Red numbers represent lengths in angstroms, green values are angles in degrees. 


\section{Non-catalytic $\mathrm{N}-\mathrm{H}$ activation energy profile}

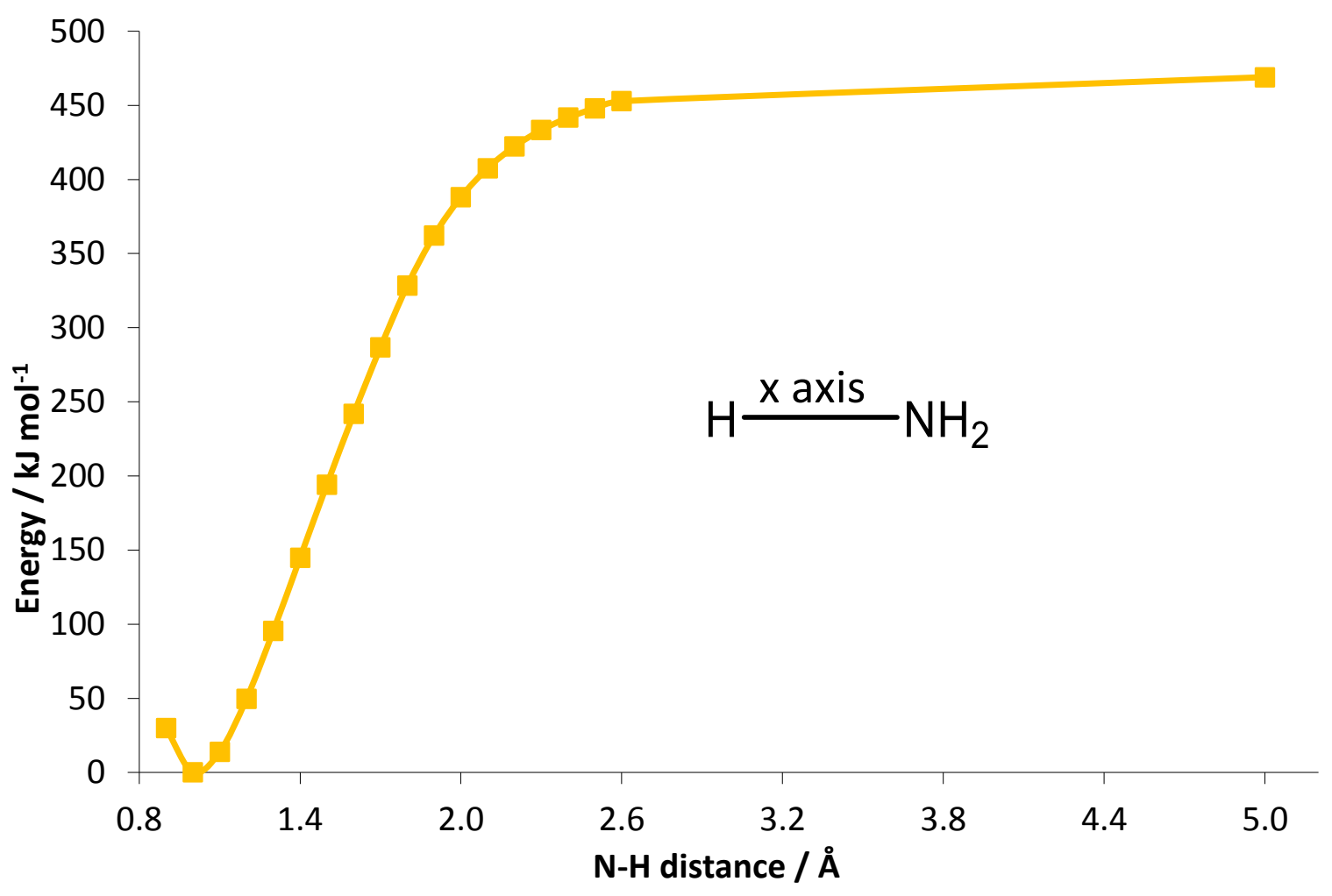

Figure S3: Energy profile showing that $470 \mathrm{~kJ} / \mathrm{mol}$ is required to break the $\mathrm{H}-\mathrm{NH}_{2}$ bond noncatalytically. 


\section{Hydrogen abstraction step}

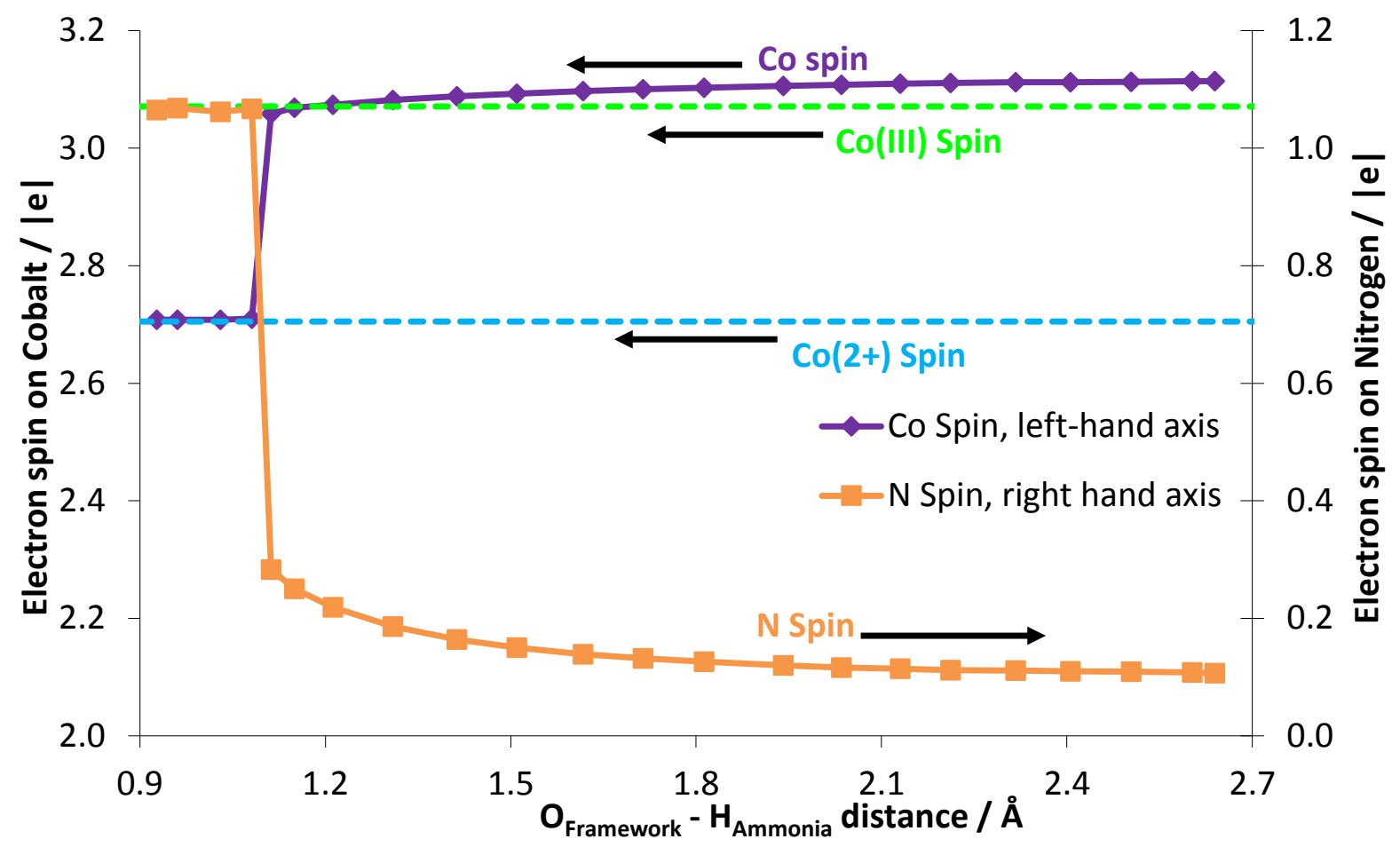

Figure S4: Spin evolution of monometallic CoAIPO-5 for the activation of ammonia.

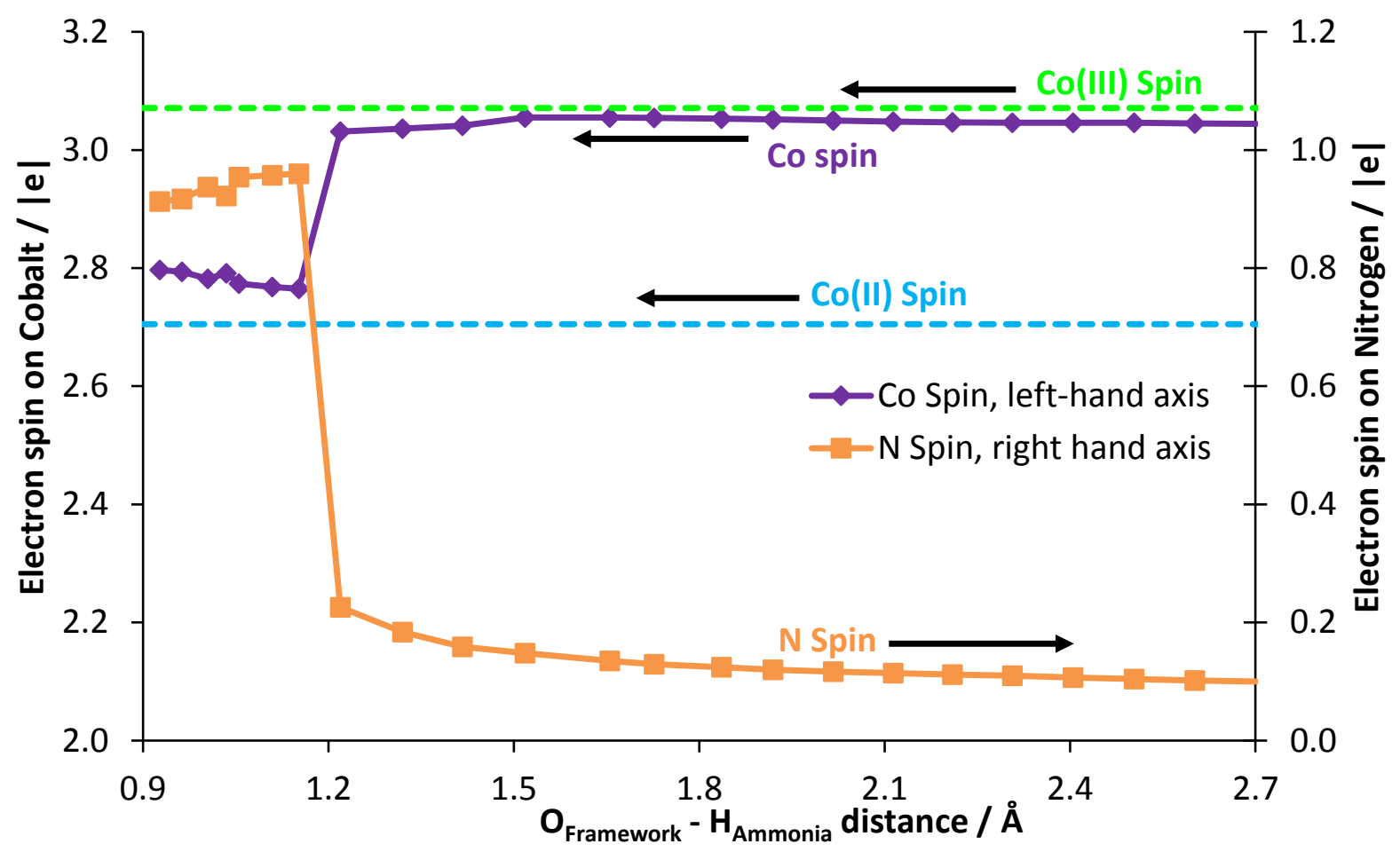

Figure S5: Spin evolution of bimetallic CoTiAlPO-5 for the activation of ammonia. 


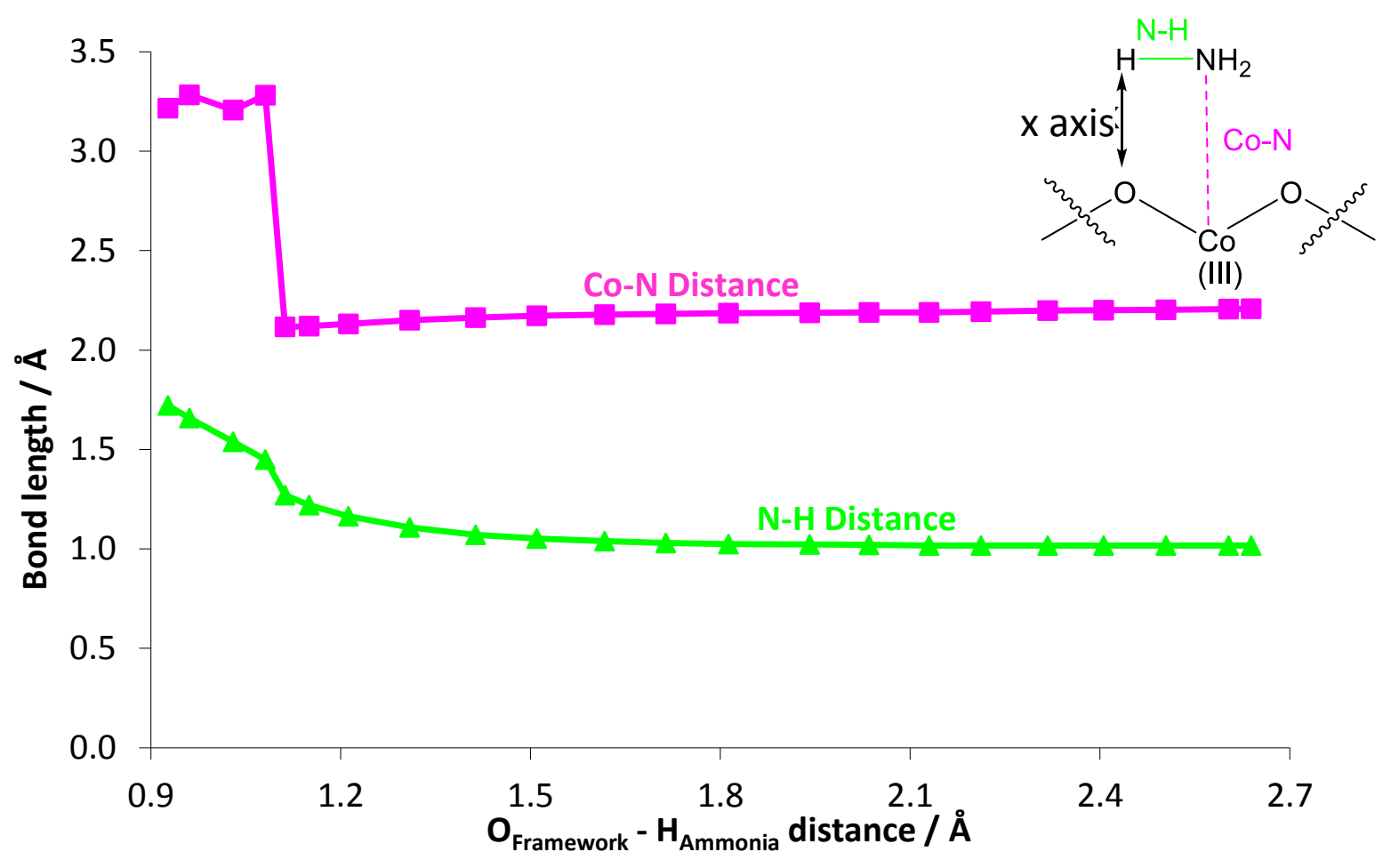

Figure S6: The evolution of bond lengths in the monometallic CoAIPO-5 system for the initial ammonia activation step.

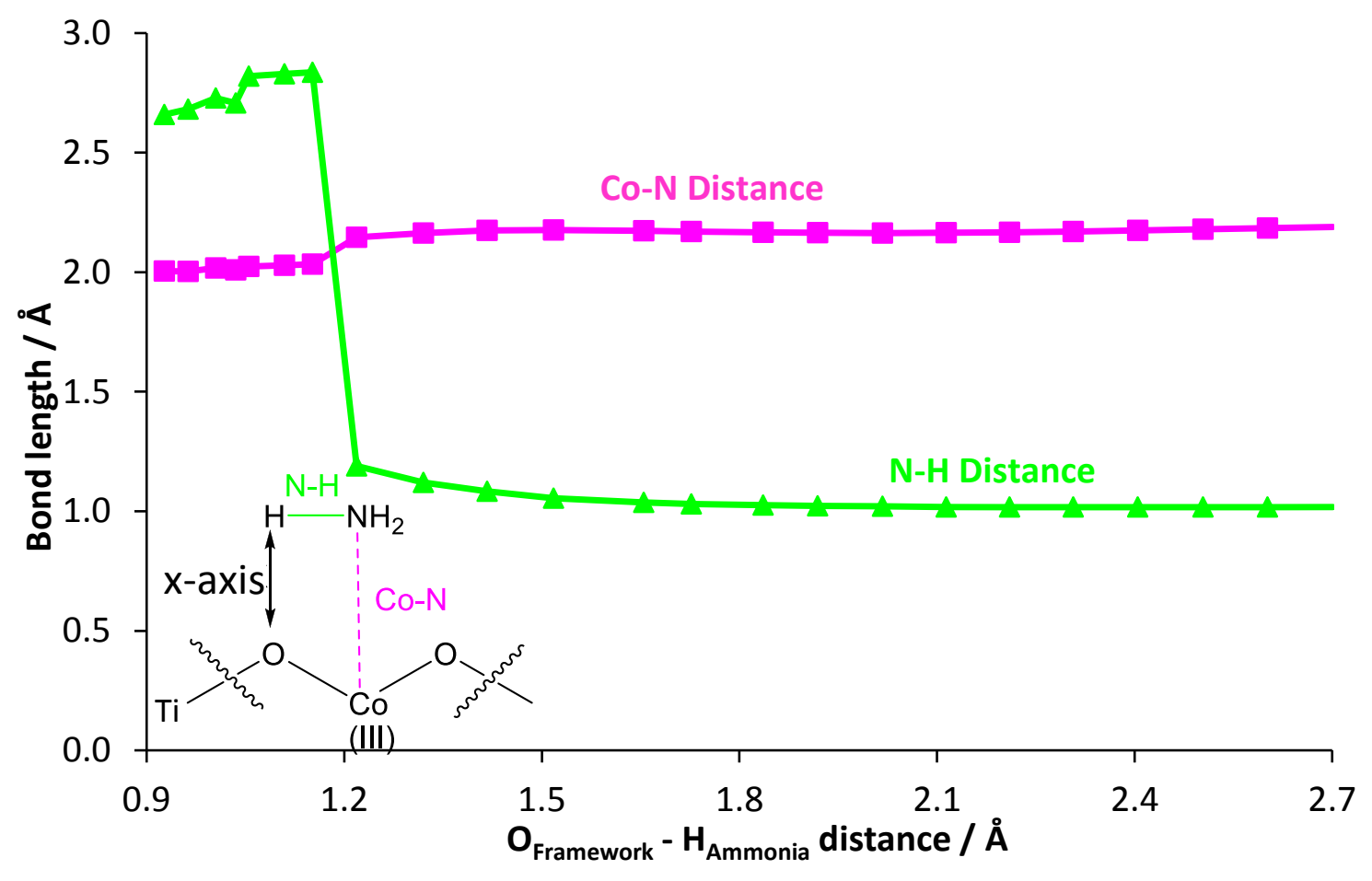

Figure S7: The evolution of bond lengths in the bimetallic CoTiAIPO-5 system for the initial ammonia activation step. 


\section{Oxygen addition step}

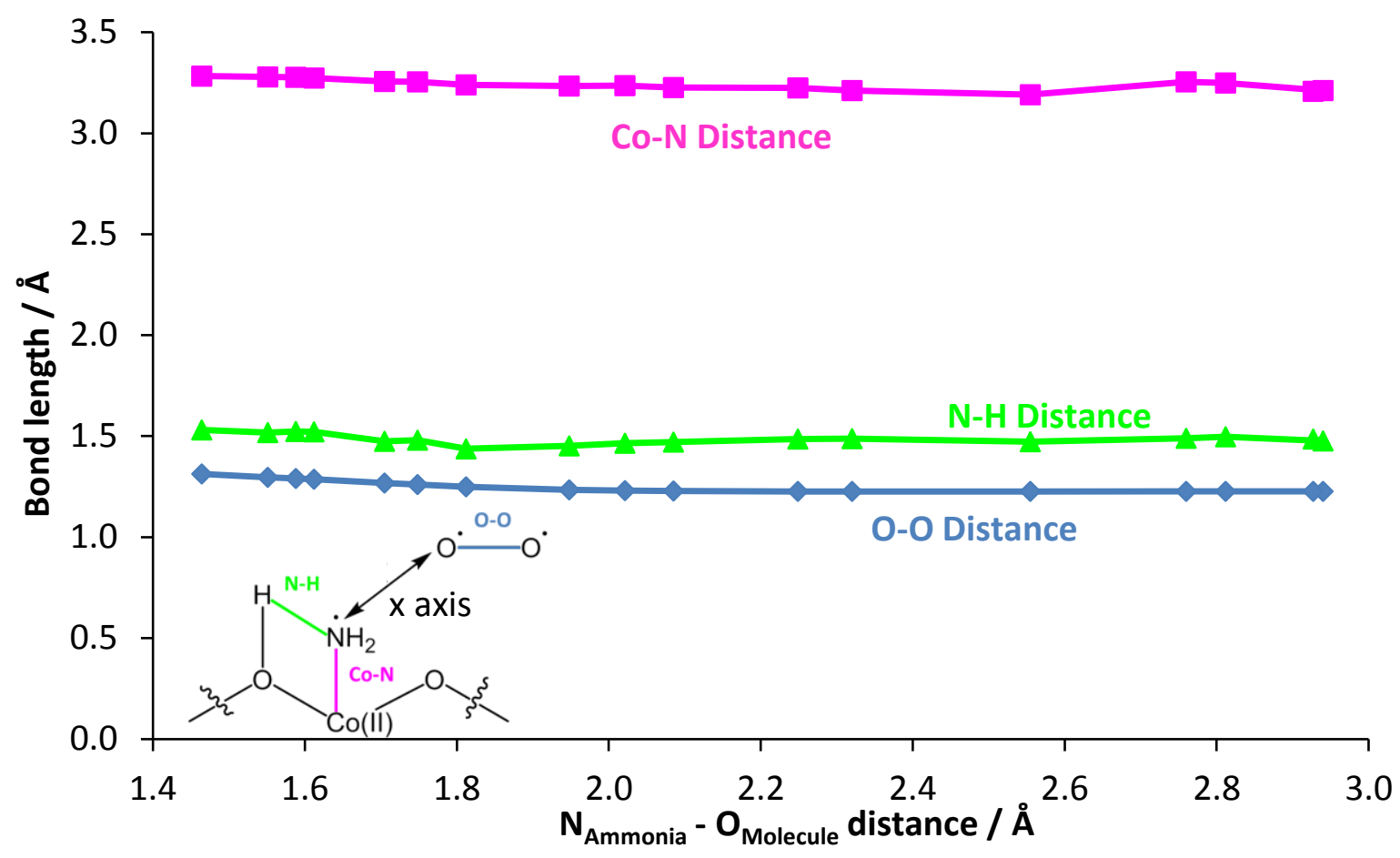

Figure S8: The evolution of bond lengths in the monometallic CoAlPO-5 system for the $\mathrm{NH}_{2} \mathrm{OO}$ formation step.

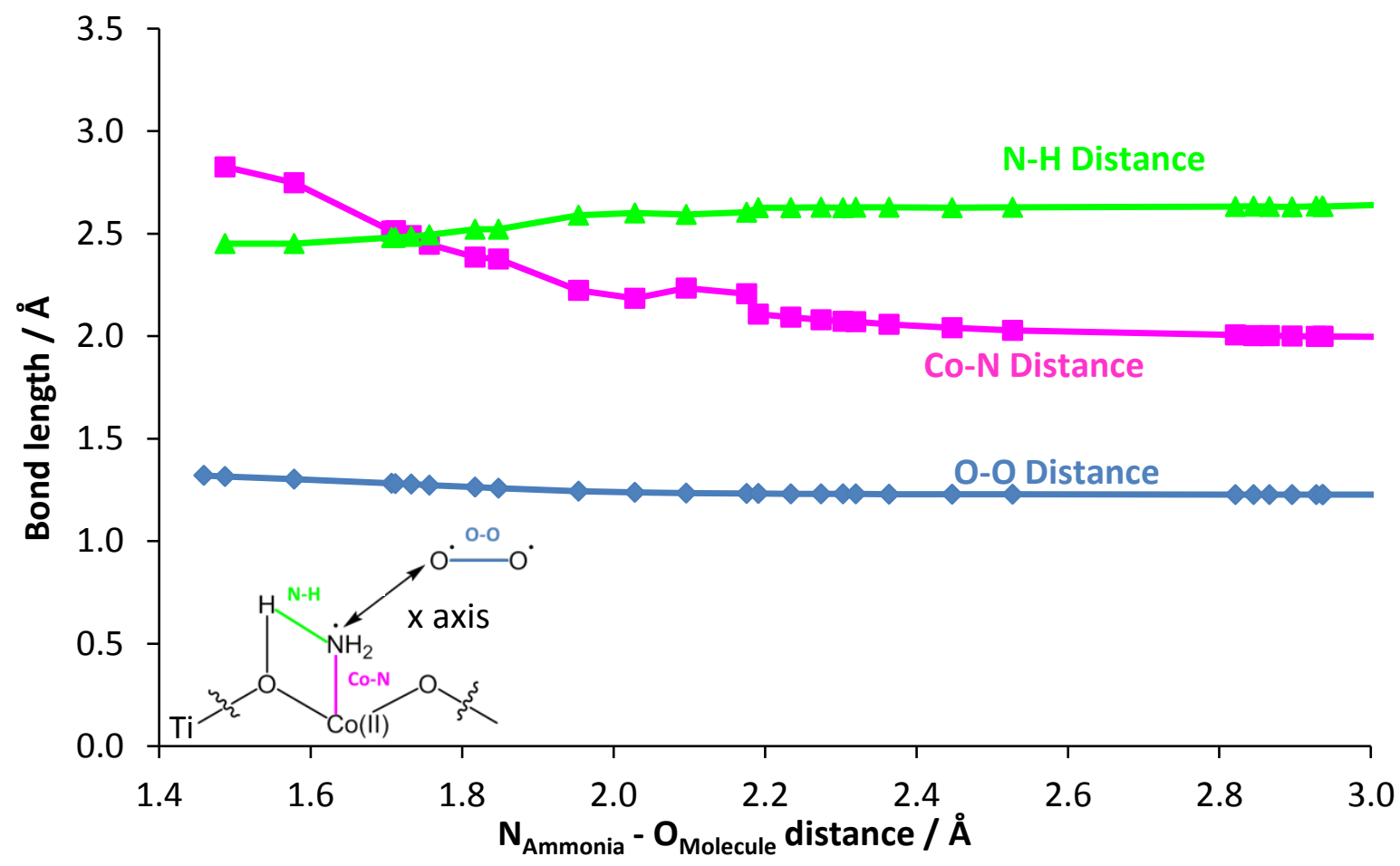

Figure S9: The evolution of bond lengths in the bimetallic CoTiAIPO-5 system for the $\mathrm{NH}_{2} \mathrm{OO}$ formation step. 


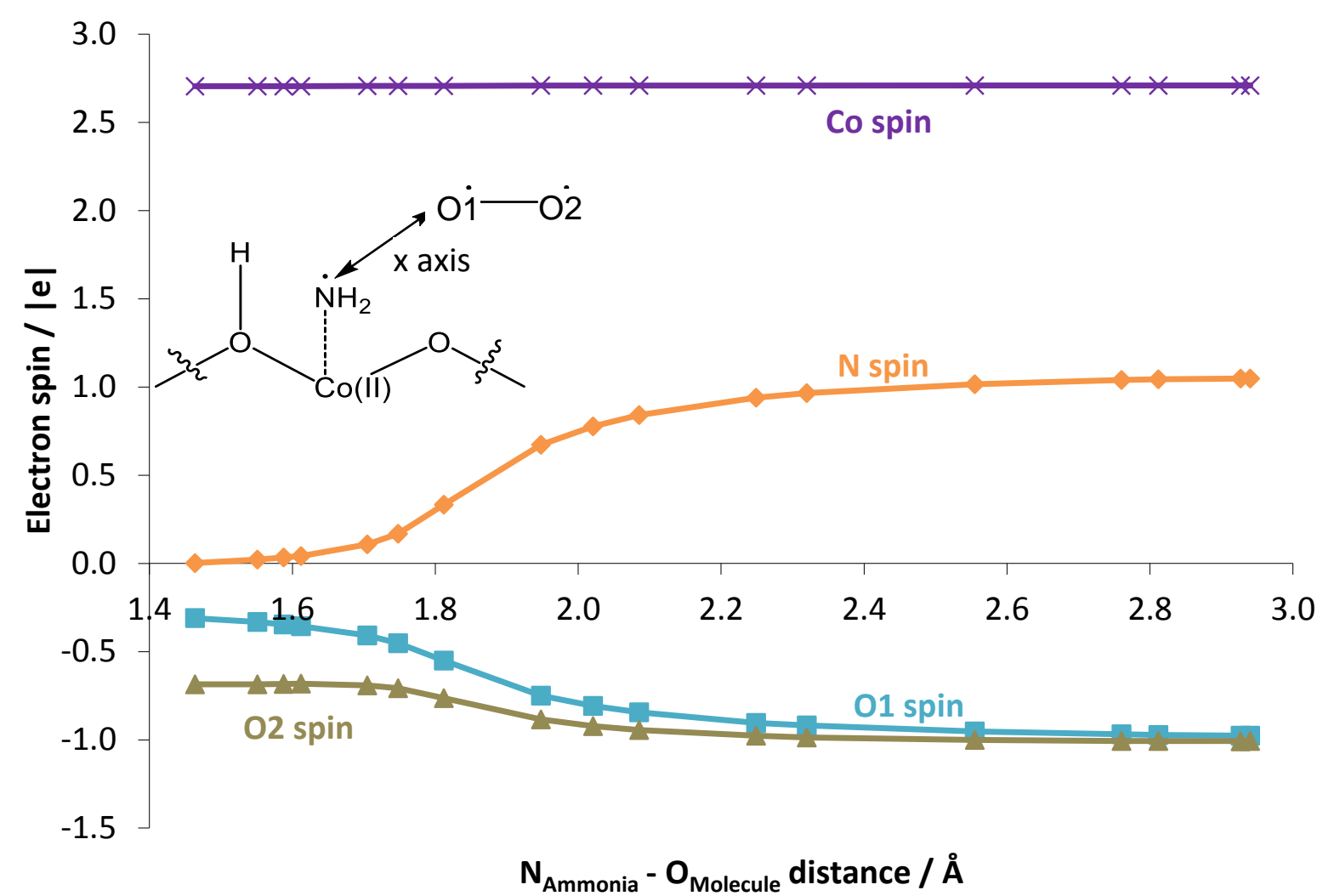

Figure S10: The evolution of spin in the monometallic CoAlPO-5 system for the formation of the $\mathrm{NH}_{2} \mathrm{OO}$ radical species.

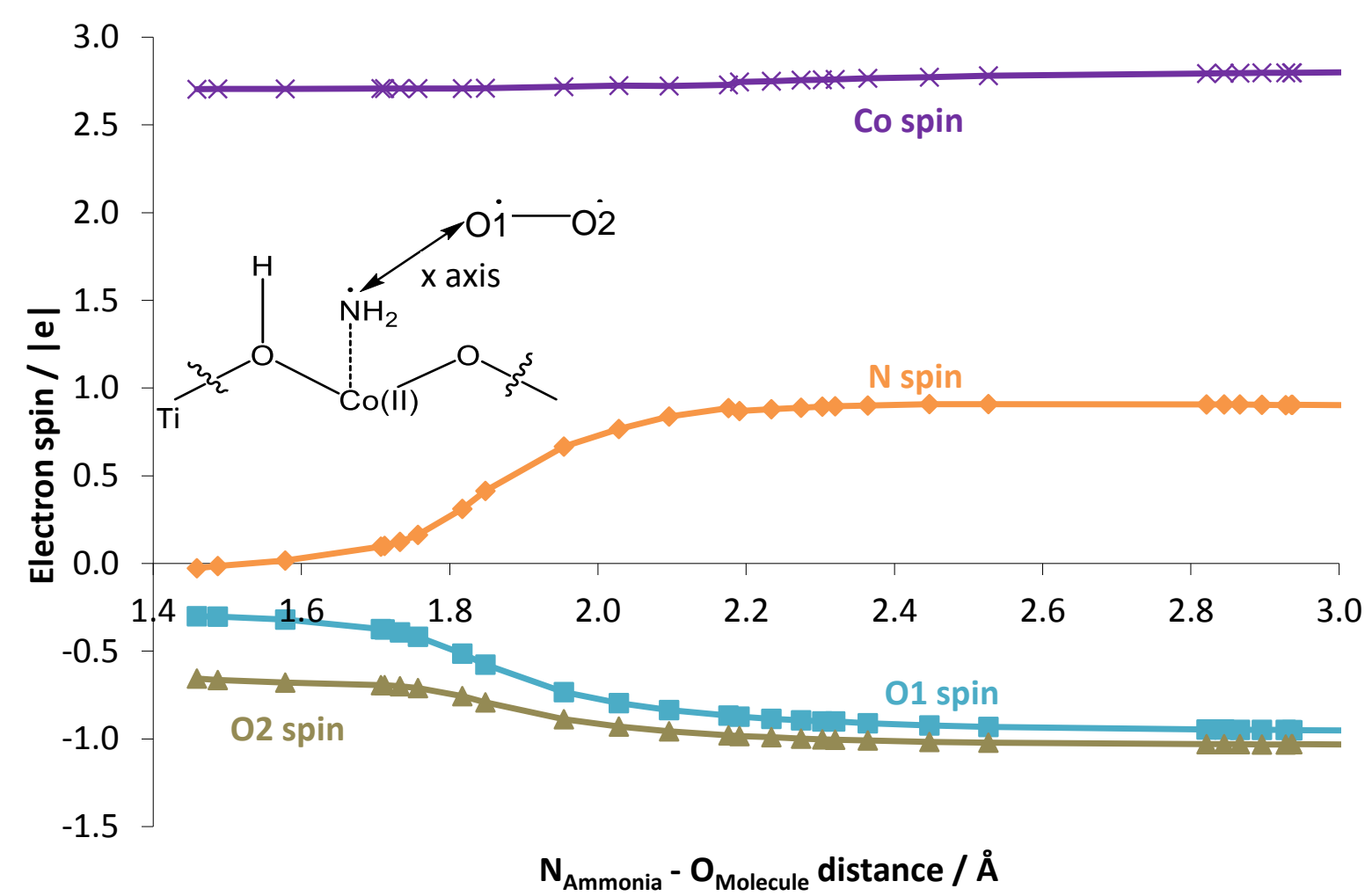

Figure S11: The evolution of spin in the bimetallic CoTiAIPO-5 system for the formation of the $\mathrm{NH}_{2} \mathrm{OO}$ radical species 
Transition state vibrational frequency calculations reported as they appear from the CRYSTAL output

\section{Monometallic hydrogen abstraction step}

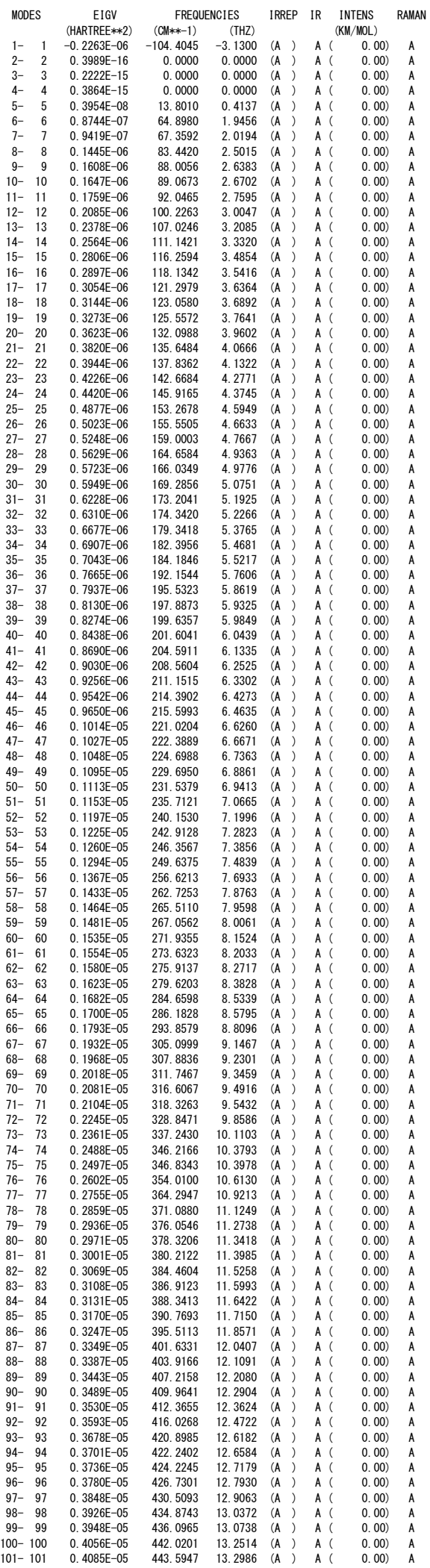

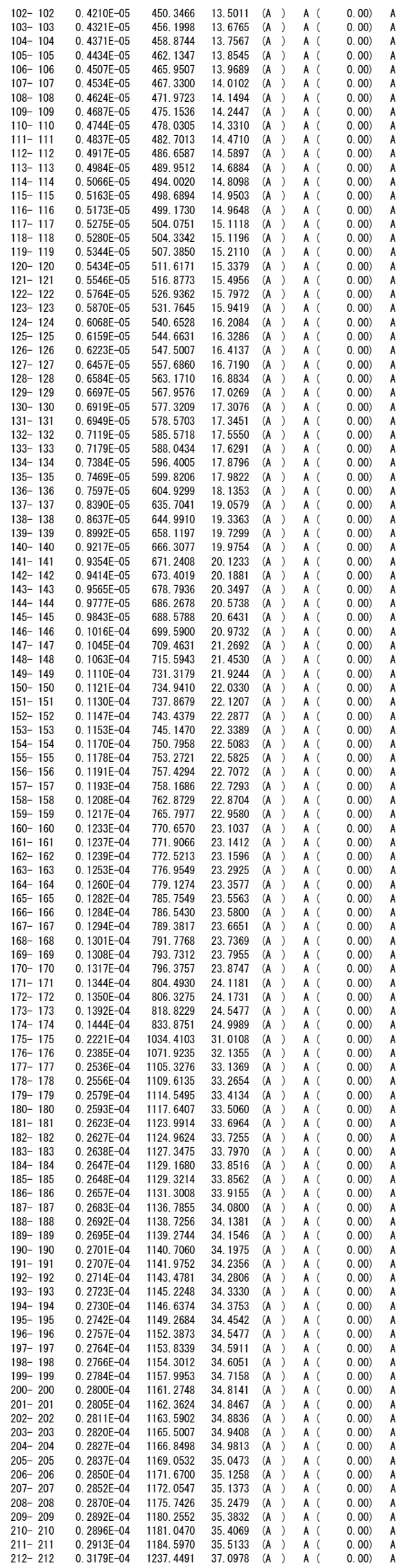




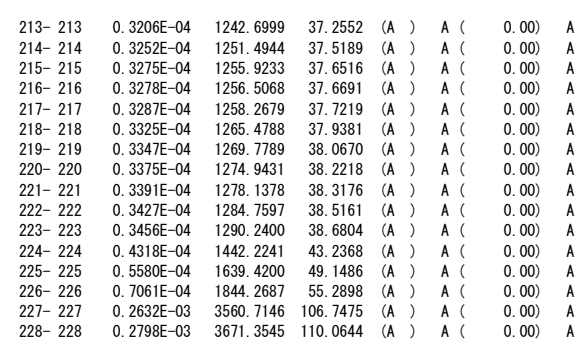

Bimetallic hydrogen abstraction

\section{step}

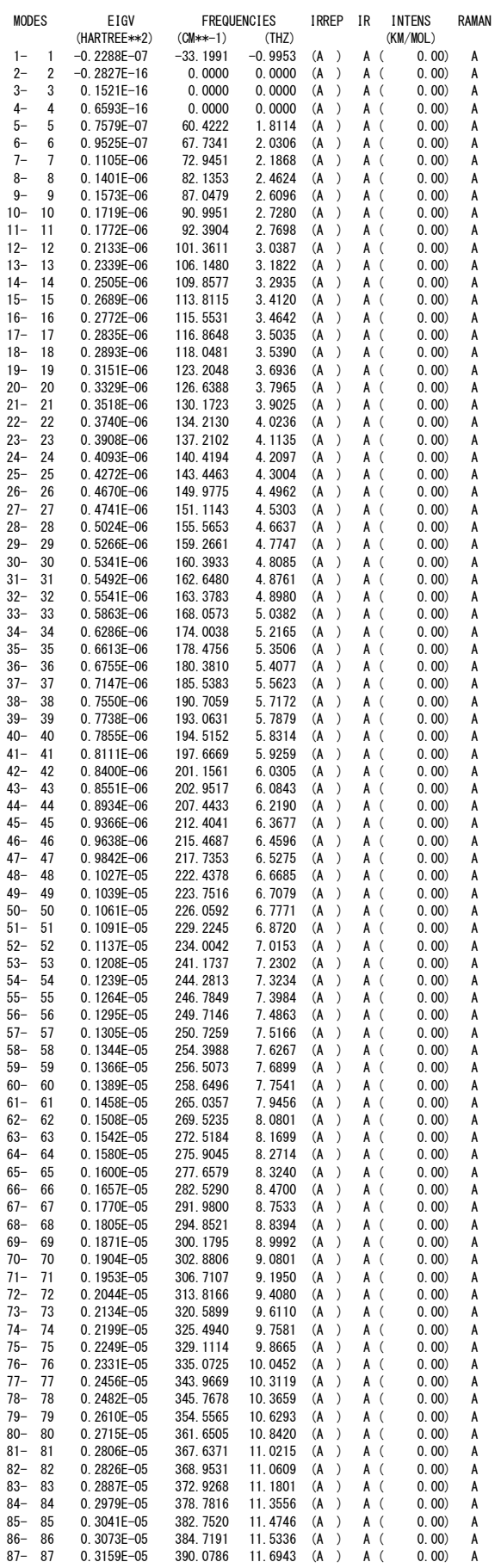

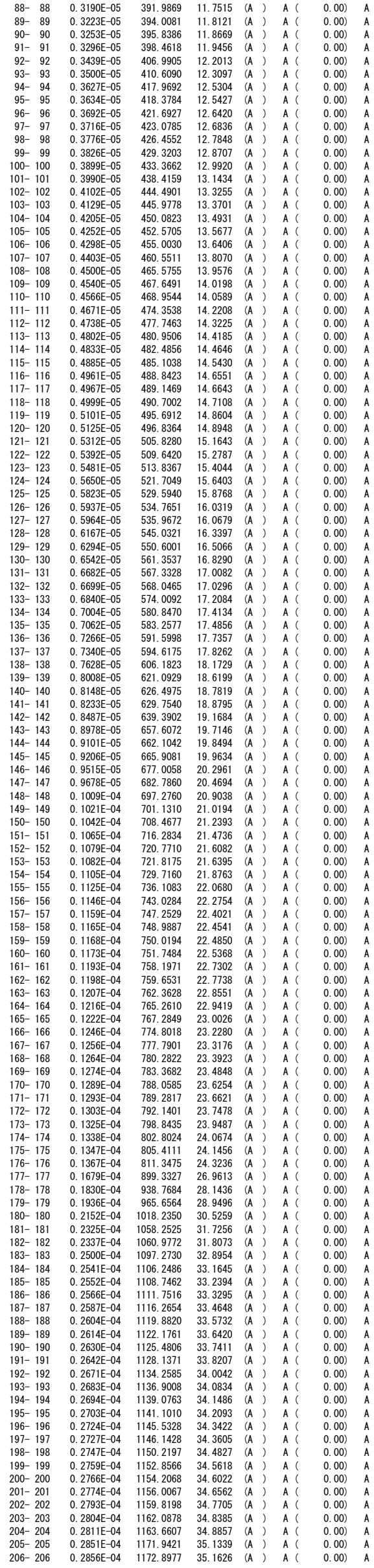




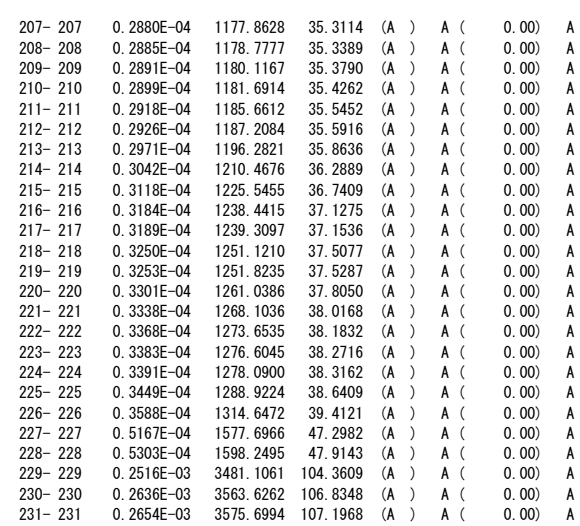

Monometallic oxygen addition step

\begin{tabular}{|c|c|c|c|c|c|c|c|}
\hline \multirow[t]{2}{*}{ MODES } & EIGV & \multicolumn{2}{|c|}{ FREQUENCIES } & IRREP & IR & INTENS & RAMAN \\
\hline & (HARTREE $* 2$ ) & & & & & (KM/MOL) & \\
\hline $1-$ & $-0.1097 \mathrm{E}-05$ & -229.8879 & -6.8919 & (A & A & $0.00)$ & A \\
\hline 2- & $0.6256 \mathrm{E}-16$ & 0.0000 & 0.0000 & (A & A & $0.00)$ & A \\
\hline & $0.8059 \mathrm{E}-16$ & 0.0000 & 0.0000 & (A & A & $0.00)$ & A \\
\hline & $0.8496 \mathrm{E}-16$ & 0.0000 & 0.0000 & (A & A & $0.00)$ & A \\
\hline & $0.2477 \mathrm{E}-07$ & 34.5390 & 1.0355 & (A & A & $0.00)$ & \\
\hline & $0.5755 E-07$ & 52.6527 & 1.5785 & (A & A & $0.00)$ & A \\
\hline 7- & $0.6387 \mathrm{E}-07$ & 55.4673 & 1.6629 & (A & A & $0.00)$ & \\
\hline $8-8$ & $0.1087 \mathrm{E}-06$ & 72. 3622 & 2. 1694 & (A & A & $0.00)$ & A \\
\hline $9-\mathrm{s}$ & $0.1138 \mathrm{E}-06$ & 74. 0282 & 2. 2193 & (A & A & $0.00)$ & A \\
\hline $10-10$ & $0.1369 \mathrm{E}-06$ & 81. 2121 & 2. 4347 & (A & A & $0.00)$ & \\
\hline & $0.1679 \mathrm{E}-06$ & 89.9422 & 2. 6964 & (A & & $0.00)$ & \\
\hline & 0. $1823 \mathrm{E}-06$ & 93.7070 & 2.8093 & (A & A & $0.00)$ & \\
\hline $13-13$ & $0.2012 E-06$ & 98.4492 & 2. 9514 & (A & A & $0.00)$ & A \\
\hline $14-$ & $0.2212 E-06$ & 103. 2235 & 3. 0946 & (A & A & $0.00)$ & \\
\hline $15-1 !$ & $0.2695 \mathrm{E}-06$ & 113.9313 & 3.4156 & (A & A & $0.00)$ & \\
\hline $16-16$ & 0. $2739 \mathrm{E}-06$ & 114.8552 & 3. 4433 & (A & A & $0.00)$ & A \\
\hline $17-17=$ & $0.2970 \mathrm{E}-06$ & 119.6171 & 3. 5860 & (A & A & $0.00)$ & \\
\hline $18-18 \mathrm{~g}=$ & $0.3056 \mathrm{E}-06$ & 121.3345 & 3.6375 & (A & A & $0.00)$ & \\
\hline $19-19$ & $0.3200 \mathrm{E}-06$ & 124. 1513 & 3. 7220 & (A & A & $0.00)$ & A \\
\hline $20-2$ & $0.3279 \mathrm{E}-06$ & 125.6752 & 3. 7676 & (A & A & $0.00)$ & A \\
\hline $21-2$ & $0.3578 E-06$ & 131.2905 & 3. 9360 & (A & A & $0.00)$ & A \\
\hline $22-$ & $0.3631 \mathrm{E}-06$ & 132.2447 & 3.9646 & (A & & $0.00)$ & \\
\hline $23-23$ & 0. $4079 \mathrm{E}-06$ & 140. 1653 & 4. 2020 & (A & A & $0.00)$ & \\
\hline $24-2$ & $0.4333 \mathrm{E}-06$ & 144. 4744 & 4. 3312 & (A & A & $0.00)$ & A \\
\hline $25-25$ & $0.4365 \mathrm{E}-06$ & 144. 9957 & 4. 3469 & (A & A & $0.00)$ & A \\
\hline $26-26$ & $0.4641 \mathrm{E}-06$ & 149. 5136 & 4. 4823 & (A & A & $0.00)$ & A \\
\hline $27-2$ & $0.4956 \mathrm{E}-06$ & 154. 5106 & 4. 6321 & (A & A & $0.00)$ & A \\
\hline $28-28$ & $0.5067 \mathrm{E}-06$ & 156. 2296 & 4. 6836 & (A & A & $0.00)$ & A \\
\hline $29-29$ & $0.5196 \mathrm{E}-06$ & 158.2108 & 4.7430 & (A & A & $0.00)$ & A \\
\hline $30-30$ & 0. $5400 \mathrm{E}-06$ & 161.2831 & 4. 8351 & (A & & $0.00)$ & \\
\hline $31-3$ & $0.5596 \mathrm{E}-06$ & 164. 1877 & 4. 9222 & (A & A & $0.00)$ & \\
\hline $32-32$ & $0.6082 \mathrm{E}-06$ & 171.1600 & 5. 1312 & (A & A & $0.00)$ & A \\
\hline $33-33$ & $0.6282 \mathrm{E}-06$ & 173. 9568 & 5. 2151 & (A & A & $0.00)$ & A \\
\hline $34-34$ & $0.6482 \mathrm{E}-06$ & 176.7064 & 5. 2975 & (A & A & $0.00)$ & A \\
\hline $35-35$ & $0.6555 \mathrm{E}-06$ & 177.6915 & 5. 3271 & (A & A & $0.00)$ & A \\
\hline $36-36=0$ & $0.6767 \mathrm{E}-06$ & 180.5438 & 5. 4126 & (A & A & $0.00)$ & A \\
\hline $37-37$ & $0.6971 \mathrm{E}-06$ & 183. 2399 & 5. 4934 & (A & A & $0.00)$ & A \\
\hline $38-38$ & $0.7087 \mathrm{E}-06$ & 184.7633 & 5. 5391 & (A & & $0.00)$ & \\
\hline $39-39$ & $0.7322 \mathrm{E}-06$ & 187. 8073 & 5.6303 & (A & A & $0.00)$ & \\
\hline $40-4 c$ & $0.7569 \mathrm{E}-06$ & 190.9464 & 5.7244 & (A & A & $0.00)$ & A \\
\hline $41-4$ & $0.7754 \mathrm{E}-06$ & 193. 2655 & 5.7940 & (A & A & $0.00)$ & A \\
\hline $42-42$ & 0. $8240 \mathrm{E}-06$ & 199. 2247 & 5. 9726 & (A & A & $0.00)$ & A \\
\hline $43-43$ & $0.8513 \mathrm{E}-06$ & 202. 5011 & 6. 0708 & (A & A & $0.00)$ & A \\
\hline $44-4$ & $0.8696 \mathrm{E}-06$ & 204.6668 & 6.1358 & (A & A & $0.00)$ & \\
\hline & $0.8755 E-06$ & 205.3560 & 6.1564 & (A & & $0.00)$ & A \\
\hline $46-46$ & $0.9257 \mathrm{E}-06$ & 211. 1591 & 6. 3304 & (A & & $0.00)$ & \\
\hline $47-47$ & $0.9402 \mathrm{E}-06$ & 212.8152 & 6. 3800 & (A & A & $0.00)$ & \\
\hline $48-48$ & $0.9617 \mathrm{E}-06$ & 215.2351 & 6. 4526 & (A & A & $0.00)$ & A \\
\hline $49-4 !$ & $0.9804 E-06$ & 217.3132 & 6.5149 & (A & A & $0.00)$ & A \\
\hline 50- & $0.1007 \mathrm{E}-05$ & 220. 1907 & 6.6012 & (A & A & $0.00)$ & A \\
\hline $51-5$ & 0. $1028 \mathrm{E}-05$ & 222. 5231 & 6.6711 & (A & A & $0.00)$ & A \\
\hline 52- & $0.1094 \mathrm{E}-05$ & 229. 5274 & 6.8811 & (A & A & $0.00)$ & A \\
\hline 53- & $0.11322-05$ & 233.5120 & 7.0005 & & & & A \\
\hline 54- & $0.1164 \mathrm{E}-05$ & 236.7928 & 7.0989 & (A & A & $0.00)$ & A \\
\hline $55-5$ & 0. $1182 \mathrm{E}-05$ & 238.5978 & 7. 1530 & (A & A & $0.00)$ & A \\
\hline $56-5$ & $0.1196 \mathrm{E}-05$ & 240.0142 & 7. 1954 & (A & A & $0.00)$ & A \\
\hline $57-5$ & $0.1250 \mathrm{E}-05$ & 245. 3560 & 7.3556 & (A & A & $0.00)$ & A \\
\hline $58-5 \varepsilon$ & $0.1293 \mathrm{E}-05$ & 249. 5173 & 7.4803 & (A & A & $0.00)$ & \\
\hline $59-59$ & 0. 1324E-05 & 252. 5113 & 7.5701 & (A & A & $0.00)$ & A \\
\hline $60-6 \mathrm{c}>\mathrm{C}$ & $0.1354 \mathrm{E}-05$ & 255.3736 & 7.6559 & (A & A & $0.00)$ & A \\
\hline $61-$ & 0. $1439 \mathrm{E}-05$ & 263. 2866 & 7.8931 & (A & & & \\
\hline $62-62$ & $0.1466 \mathrm{E}-05$ & 265.7666 & 7. 9675 & (A & A & $0.00)$ & A \\
\hline $63-63$ & $0.1475 \mathrm{E}-05$ & 266.5923 & 7. 9922 & (A & A & $0.00)$ & A \\
\hline & $0.1515 \mathrm{E}-$ & 270. 1076 & 8. 0976 & (A & A & $0.00)$ & A \\
\hline $65-65$ & $0.1551 \mathrm{E}-05$ & 273. 2982 & 8. 1933 & (A & A & $0.00)$ & A \\
\hline $66-66$ & $0.1595 E-05$ & 277. 1835 & 8. 3098 & & & $0.00)$ & A \\
\hline $67-67$ & $0.1634 \mathrm{E}-05$ & 280.5328 & 8.4102 & (A & A & $0.00)$ & A \\
\hline $68-$ & $0.1669 \mathrm{E}-05$ & 283.5016 & 8.4992 & & & $0.00)$ & A \\
\hline $69-$ & 0.172 & 288.2 & 8.6426 & & & & \\
\hline $70-7 c$ & $0.1758 \mathrm{E}-05$ & 291.0003 & 8.7240 & (A & A & $0.00)$ & A \\
\hline $71-7$ & & & & (A & A & & A \\
\hline $72-72$ & $0.1863 \mathrm{E}-$ & 299.5 & 8.98 & (A & A & $0.00)$ & A \\
\hline $73-73$ & $0.1909 \mathrm{E}-05$ & 303. 2172 & 9. 0902 & (A & A & $0.00)$ & A \\
\hline $74-74$ & $0.1958 \mathrm{E}-05$ & 307.1024 & 9. 2067 & (A & A & $0.00)$ & A \\
\hline & 0. $2080 \mathrm{E}-05$ & 316. 4966 & 9. 4883 & & & $0.00)$ & A \\
\hline 76- & 0. & 2.0 & 96542 & & & $0.00)$ & A \\
\hline & 0. & $329.8 \mathrm{~g} \quad \mathrm{C}$ & 9. 8892 & & & 0.00 & \\
\hline & & 339.4 & 10.17 & & A & & \\
\hline & & & & & A & $0.00)$ & $\mathrm{A}$ \\
\hline $80-80$ & 0. $2608 \mathrm{E}-05$ & 354. 4317 & 10.6256 & (A & A & $0.00)$ & A \\
\hline $81-8$ & $0.2705 \mathrm{E}-05$ & 360.9862 & 10.8221 & (A) & A & $0.00)$ & A \\
\hline
\end{tabular}

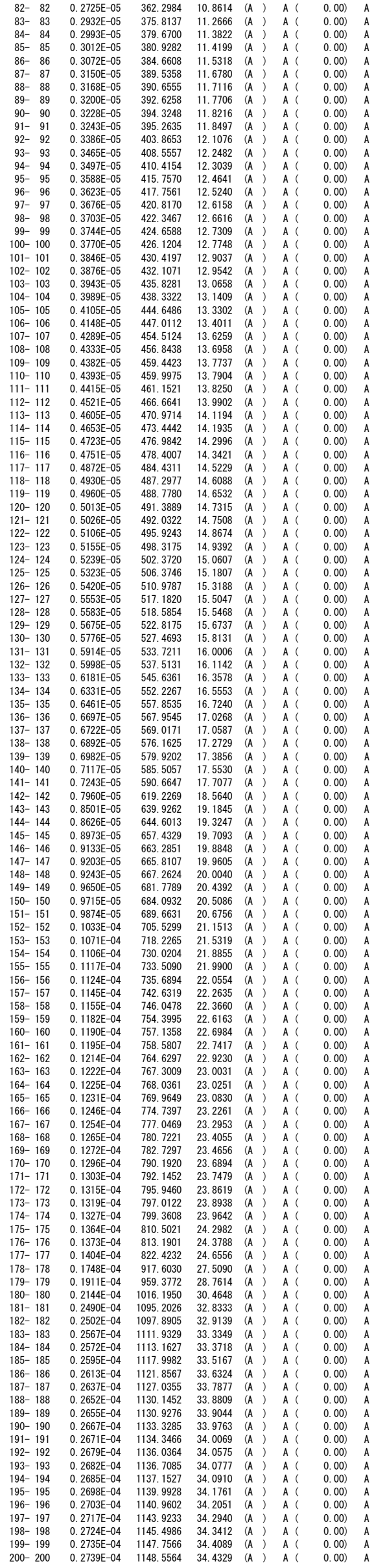




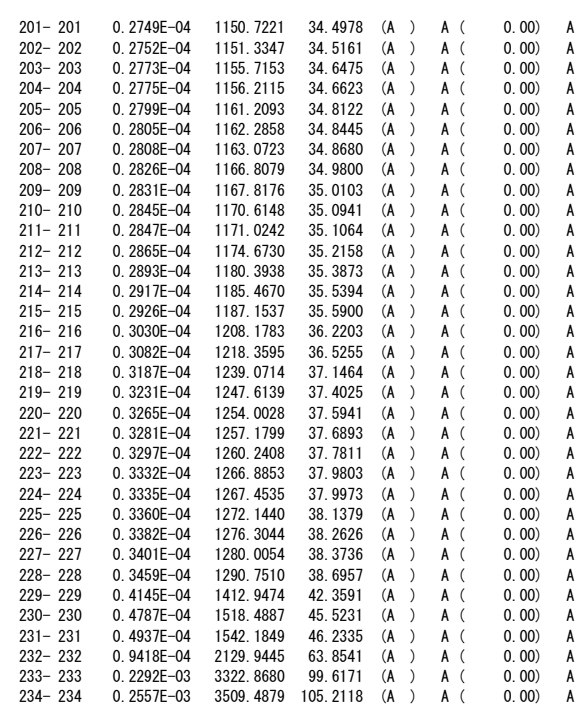

Bimetallic oxygen addition step

\begin{tabular}{|c|c|c|c|c|c|c|c|}
\hline MODES & EIGV & FREQUE & NCIES & IRREP & IR & INTENS & RAMAN \\
\hline & (HARTREE $* 2$ ) & $(\mathrm{CM} * *-1)$ & (THZ) & & & (KM/MOL) & \\
\hline $1-$ & $-0.1049 \mathrm{E}-05$ & -224.8364 & -6.7404 & (A & A & $0.00)$ & \\
\hline $2-$ & $0.2146 \mathrm{E}-16$ & 0.0000 & 0.0000 & (A & A & $0.00)$ & A \\
\hline $3-3$ & $0.4345 \mathrm{E}-16$ & 0.0000 & 0.0000 & (A & A & $0.00)$ & A \\
\hline & $0.5342 \mathrm{E}-16$ & 0.0000 & 0.0000 & (A & A & $0.00)$ & A \\
\hline & $0.5480 \mathrm{E}-07$ & 51. 3787 & 1. 5403 & (A & A & $0.00)$ & A \\
\hline & $0.7283 \mathrm{E}-07$ & 59. 2280 & 1.7756 & (A & A & $0.00)$ & \\
\hline & $0.9230 \mathrm{E}-07$ & 66.6782 & 1.9990 & (A & A & $0.00)$ & \\
\hline & $0.1092 E-06$ & 72.5206 & 2. 1741 & (A & A & $0.00)$ & \\
\hline & $0.1346 \mathrm{E}-06$ & 80.5251 & 2. 4141 & (A & A & $0.00)$ & \\
\hline $10-10$ & $0.1466 \mathrm{E}-06$ & 84. 0471 & 2. 5197 & (A & A & $0.00)$ & \\
\hline $11-11$ & $0.1562 \mathrm{E}-06$ & 86.7399 & 2. 6004 & (A & A & $0.00)$ & A \\
\hline & $0.1659 \mathrm{E}-06$ & 89.3814 & 2. 6796 & (A & A & $0.00)$ & \\
\hline & $0.1830 \mathrm{E}-06$ & 93.8828 & 2.8145 & (A & A & $0.00)$ & \\
\hline & $0.1975 \mathrm{E}-06$ & 97.5428 & 2. 9243 & (A & A & $0.00)$ & \\
\hline $15-15$ & 0. $2238 \mathrm{E}-06$ & 103. 8302 & 3. 1128 & (A & A & $0.00)$ & \\
\hline $16-16 \quad>>$ & $0.2424 E-06$ & 108.0466 & 3. 2392 & (A & A & $0.00)$ & A \\
\hline $17-$ & $0.2522 \mathrm{E}-06$ & 110. 2088 & 3. 3040 & (A & A & $0.00)$ & \\
\hline $18-18$ & $0.2660 \mathrm{E}-06$ & 113.1867 & 3. 3933 & (A & A & $0.00)$ & \\
\hline $19-19$ & 0. $2874 \mathrm{E}-06$ & 117.6683 & 3. 5276 & (A & A & $0.00)$ & \\
\hline $20-20$ & $0.2994 \mathrm{E}-06$ & 120.0990 & 3. 6005 & (A & A & $0.00)$ & \\
\hline $21-21$ & $0.3136 \mathrm{E}-06$ & 122. 9039 & 3. 6846 & (A & A & $0.00)$ & \\
\hline $22-22$ & $0.3181 \mathrm{E}-06$ & 123. 7831 & 3.7109 & (A & A & $0.00)$ & \\
\hline 23- 23 & $0.3330 \mathrm{E}-06$ & 126.6477 & 3. 7968 & (A & A & $0.00)$ & \\
\hline 24- 24 & $0.3605 \mathrm{E}-06$ & 131.7811 & 3. 9507 & (A & A & $0.00)$ & A \\
\hline 25- & 0. $3860 \mathrm{E}-06$ & 136. 3510 & 4. 0877 & (A & & $0.00)$ & \\
\hline $26-26$ & $0.3913 \mathrm{E}-06$ & 137. 2959 & 4. 1160 & (A & A & $0.00)$ & \\
\hline $27-27$ & $0.4111 \mathrm{E}-06$ & 140.7158 & 4. 2186 & (A & A & $0.00)$ & \\
\hline $28-28$ & $0.4195 \mathrm{E}-06$ & 142. 1522 & 4. 2616 & (A & A & $0.00)$ & \\
\hline $29-29$ & $0.4479 \mathrm{E}-06$ & 146.8790 & 4. 4033 & (A & A & $0.00)$ & A \\
\hline $30-30$ & $0.4509 \mathrm{E}-06$ & 147. 3711 & 4. 4181 & (A & A & $0.00)$ & \\
\hline $31-31$ & $0.4822 \mathrm{E}-06$ & 152.4030 & 4. 5689 & (A & A & $0.00)$ & \\
\hline $32-32$ & 0. $5097 \mathrm{E}-06$ & 156.6860 & 4. 6973 & (A & A & $0.00)$ & \\
\hline $33-$ & $0.5237 \mathrm{E}-06$ & 158.8244 & 4. 7614 & (A & & $0.00)$ & \\
\hline 34- 34 & $0.5497 \mathrm{E}-06$ & 162.7181 & 4. 8782 & (A & A & $0.00)$ & A \\
\hline $35-35$ & $0.5561 \mathrm{E}-06$ & 163.6602 & 4. 9064 & (A & A & $0.00)$ & A \\
\hline $36-36$ & $0.5767 \mathrm{E}-06$ & 166.6738 & 4. 9968 & (A & A & $0.00)$ & A \\
\hline $37-37$ & $0.6415 \mathrm{E}-06$ & 175.7839 & 5. 2699 & (A & A & $0.00)$ & A \\
\hline 38- 38 & $0.6612 \mathrm{E}-06$ & 178.4613 & 5. 3501 & (A & A & $0.00)$ & A \\
\hline & $0.6805 \mathrm{E}-06$ & 181.0474 & 5. 4277 & (A & A & $0.00)$ & \\
\hline $40-40$ & $0.6961 \mathrm{E}-06$ & 183. 1083 & 5. 4894 & (A & & $0.00)$ & \\
\hline $41-41$ & $0.7206 \mathrm{E}-06$ & 186. 3077 & 5.5854 & (A & A & $0.00)$ & \\
\hline $42-\quad 42$ & $0.7541 \mathrm{E}-06$ & 190.5949 & 5.7139 & (A & A & $0.00)$ & A \\
\hline 43- 43 & $0.7814 \mathrm{E}-06$ & 194. 0053 & 5.8161 & (A & A & $0.00)$ & A \\
\hline 44- 44 & $0.8116 \mathrm{E}-06$ & 197.7201 & 5.9275 & (A & A & $0.00)$ & \\
\hline $45-45$ & $0.8307 \mathrm{E}-06$ & 200.0412 & 5. 9971 & (A & A & $0.00)$ & A \\
\hline & $0.8464 \mathrm{E}-06$ & 201.9190 & 6.0534 & (A & A & $0.00)$ & \\
\hline $47-47$ & $0.8541 \mathrm{E}-06$ & 202. 8381 & 6. 0809 & (A & A & $0.00)$ & \\
\hline 48- 48 & $0.9170 \mathrm{E}-06$ & 210.1678 & 6. 3007 & (A & & $0.00)$ & A \\
\hline 49- 49 & $0.9469 \mathrm{E}-06$ & 213. 5664 & 6. 4026 & (A & A & $0.00)$ & A \\
\hline $50-50$ & 0. $9552 \mathrm{E}-06$ & 214. 4971 & 6. 4305 & (A & A & $0.00)$ & A \\
\hline $51-51$ & $0.9706 \mathrm{E}-06$ & 216. 2274 & 6.4823 & (A & A & $0.00)$ & \\
\hline & $0.1011 \mathrm{E}-05$ & 220.6980 & 6.6164 & (A & A & $0.00)$ & \\
\hline & $0.1030 \mathrm{E}-05$ & 222.7526 & 6.6780 & (A & A & $0.00)$ & \\
\hline 54- 54 & $0.1046 E-05$ & 224.4413 & 6.7286 & (A & A & $0.00)$ & A \\
\hline $55-55$ & 0. $1092 \mathrm{E}-05$ & 229. 3295 & 6.8751 & (A & A & $0.00)$ & \\
\hline $56-56$ & $0.1171 \mathrm{E}-05$ & 237. 4801 & 7.1195 & (A & A & $0.00)$ & A \\
\hline $57-\quad 57$ & 0. 1191E-05 & 239. 4913 & 7. 1798 & (A & A & $0.00)$ & A \\
\hline $58-\quad 58$ & $0.1226 \mathrm{E}$ & 243. 0232 & 7. 2857 & (A & A & $0.00)$ & A \\
\hline $59-59$ & $0.1260 \mathrm{E}-\mathrm{Z}$ & 246. 31 & 7.3843 & (A & A & $0.00)$ & A \\
\hline $60-60$ & $0.1262 \mathrm{E}-05$ & 246.5187 & 7.3904 & (A & A & $0.00)$ & A \\
\hline $61-61$ & $0.1293 \mathrm{E}-05$ & 249. 5178 & 7. 4804 & (A & A & $0.00)$ & A \\
\hline $62-\quad 62$ & $0.1325 \mathrm{E}-05$ & 252. 5947 & 7.5726 & (A & A & $0.00)$ & A \\
\hline & $0.1374 \mathrm{E}-05$ & 257. 2847 & 7.7132 & (A & & $0.00)$ & A \\
\hline & $0.1399 \mathrm{E}$ & 259.6 & 7.7835 & (A & & 0.0 & \\
\hline & & 2 & 8.08 & (A & & 0.0 & \\
\hline 66- & & & 8.09 & (A & A & 0.0 & A \\
\hline $67-\quad 67$ & $0.1544 \mathrm{E}-05$ & 272.7427 & 8.1766 & (A & A & $0.00)$ & A \\
\hline $68-68$ & $0.1586 \mathrm{E}-05$ & 276. 4331 & 8. 2873 & (A & A & $0.00)$ & A \\
\hline $69-69$ & $0.1646 \mathrm{E}-05$ & 281.6120 & 8. 4425 & (A & A & $0.00)$ & A \\
\hline $70-70$ & $0.1711 \mathrm{E}-05$ & 287. 1103 & 8. 6074 & (A & A & $0.00)$ & A \\
\hline & $1702=0$ & 289.7948 & 8. 6878 & & & & \\
\hline 72- & $0.1771 \mathrm{E}-05$ & 292. 0737 & 8.75 & & & & \\
\hline & & & 62 & & & & \\
\hline & & & & & & & \\
\hline
\end{tabular}

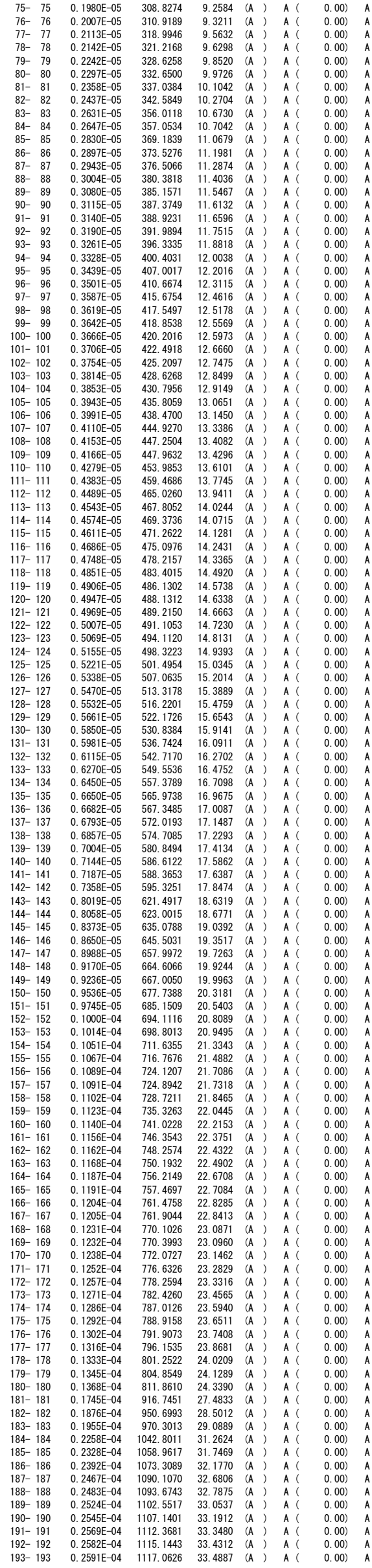




\begin{tabular}{|c|c|c|c|c|c|c|}
\hline 194- 194 & $0.2616 \mathrm{E}-04$ & 1122.5774 & 33.6540 & (A & A & $0.00)$ \\
\hline 95- 195 & 0. $2631 \mathrm{E}-04$ & 1125.7401 & 33.7488 & & A & 0.00 ) \\
\hline 196 & 0. $2647 \mathrm{E}-04$ & 1129. 1015 & 33. 8496 & (A & A & \\
\hline-197 & $2655 \mathrm{E}-04$ & 1130.9515 & 33. 9051 & $(A)$ & A & 0. 00) \\
\hline $198-198$ & $0.2665 \mathrm{E}-04$ & 1133.0041 & 33.9666 & (A & A & $0.00)$ \\
\hline $199-199$ & $0.2678 \mathrm{E}-04$ & 1135.8230 & 34. 0511 & (A & A & $0.00)$ \\
\hline $200-200$ & $0.2689 \mathrm{E}-04$ & 1138.1383 & 34.1205 & (A & A & $0.00)$ \\
\hline $201-201$ & 0. 2698E-04 & 1140.0039 & 34.1765 & (A & A & 0.00 ) \\
\hline $202-202$ & 0. 2712E-04 & 1143. 0591 & 34.2680 & (A & A & 0.00 ) \\
\hline $203-203$ & 0. $2725 \mathrm{E}-04$ & 1145.6750 & 34. 3465 & (A & $\hat{A}$ & 0.00 ) \\
\hline 204- 204 & $0.2743 E-04$ & 1149.5039 & 34. 4613 & (A & A & $0.00)$ \\
\hline 205- 205 & $0.2758 \mathrm{E}-04$ & 1152.6179 & 34.5546 & (A & A & $0.00)$ \\
\hline 206- 206 & $0.2782 E-04$ & 1157.7153 & 34. 7074 & (A & A & $0.00)$ \\
\hline 207- 207 & $0.2787 \mathrm{E}-04$ & 1158.6872 & 34.7366 & (A & & $0.00)$ \\
\hline $208-208$ & $0.2794 \mathrm{E}-04$ & 1160.1868 & 34.7815 & (A & A & $0.00)$ \\
\hline $209-209$ & $0.2806 \mathrm{E}-04$ & 1162.6350 & 34.8549 & (A & A & 0.00 ) \\
\hline $210-210$ & $0.2824 \mathrm{E}-04$ & 1166. 3220 & 34.9655 & (A & A & 0.00 ) \\
\hline $211-211$ & $2829 \mathrm{E}-04$ & 1167.3274 & 34. 9956 & & A & 0.00 ) \\
\hline-212 & $7 E-04$ & 1171.1 & & & & 0) \\
\hline $213-213$ & $0.2856 \mathrm{E}-04$ & 1172.8394 & & (A & A & $0.00)$ \\
\hline $214-214$ & $0.2885 \mathrm{E}-04$ & 1178.8789 & 35.3419 & (A & A & $0.00)$ \\
\hline $215-215$ & $0.2886 \mathrm{E}-04$ & 1179.0546 & 35. 3472 & (A & A & $0.00)$ \\
\hline $216-216$ & $0.2892 E-04$ & 1180. 2213 & 35. 3821 & (A & A & $0.00)$ \\
\hline $217-217$ & $0.2923 \mathrm{E}-04$ & 1186.6513 & 35.5749 & (A & A & 0.00 ) \\
\hline $218-218$ & 0. 2954E-04 & 1192.9400 & 35.7634 & (A & A & 0.00 ) \\
\hline $219-219$ & $0.2956 \mathrm{E}-04$ & 1193.1779 & & & A & 0.00 ) \\
\hline 220 & 04 & 1212. & 36. 3 & & & \\
\hline $221-221$ & $0.3180 \mathrm{E}-04$ & 1237.7286 & 37. 1062 & (A & A & $0.00)$ \\
\hline $222-222$ & $0.3196 \mathrm{E}-04$ & 1240.7514 & 37.1968 & (A & A & $0.00)$ \\
\hline $223-223$ & $0.3208 \mathrm{E}-04$ & 1243. 0382 & 37.2653 & (A & A & $0.00)$ \\
\hline 224- 224 & $0.3272 \mathrm{E}-04$ & 1255. 3372 & 37.6341 & & A & $0.00)$ \\
\hline 225- 225 & $0.3275 \mathrm{E}-04$ & 1256.0770 & 37. 6562 & & A & $0.00)$ \\
\hline $226-226$ & $0.3331 \mathrm{E}-04$ & 1266.6325 & 37.9727 & (A & A & $0.00)$ \\
\hline 227- 227 & $0.3360 \mathrm{E}-04$ & 1272. 2175 & 38.1401 & & A & 0.00 ) \\
\hline $228-228$ & $0.3388 \mathrm{E}-$ & 1277.4900 & 38. 2982 & & & 0) \\
\hline $229-229$ & $0.3424 \mathrm{E}-04$ & 1284. 3380 & 38.5035 & (A & & 0.00 ) \\
\hline $230-230$ & $0.3458 \mathrm{E}-04$ & 1290.6902 & & & A & $0.00)$ \\
\hline & $0.4332 \mathrm{E}-04$ & 1444. 4853 & 43.3 & & A & $0.00)$ \\
\hline $232-232$ & $0.5193 E-04$ & 1581.6154 & 47.4156 & (A & A & 0.00 ) \\
\hline & $0.2491 \mathrm{E}-03$ & 3463. 8488 & 103. 8436 & & A & $0.00)$ \\
\hline & Cons & 3557.6053 & & & & $0.00)$ \\
\hline & 0. 2639E-03 & 65.0860 & 6. 8786 & & & $0.00)$ \\
\hline i- 23 & $0.3138 \mathrm{E}-03$ & 3888.0400 & 6.5605 & & & $0.00)$ \\
\hline
\end{tabular}




\section{$\underline{\text { Transition state figures }}$}

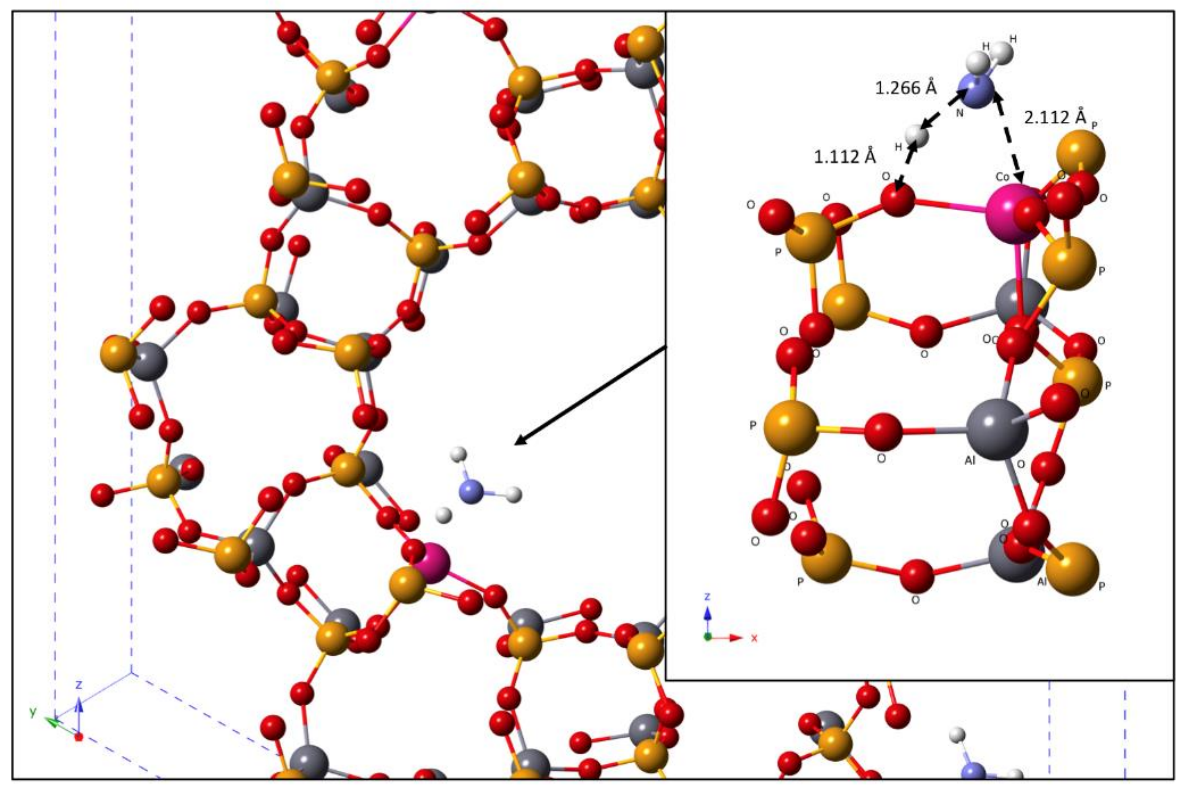

Figure S12: The calculated transition state for the monometallic CoAlPO-5 system during the hydrogen abstraction step. Pink $=$ Cobalt, Red $=$ Oxygen, Yellow $=$ Phosphorus, Grey $=$ Aluminium, White $=$ Hydrogen, Blue $=$ Nitrogen .

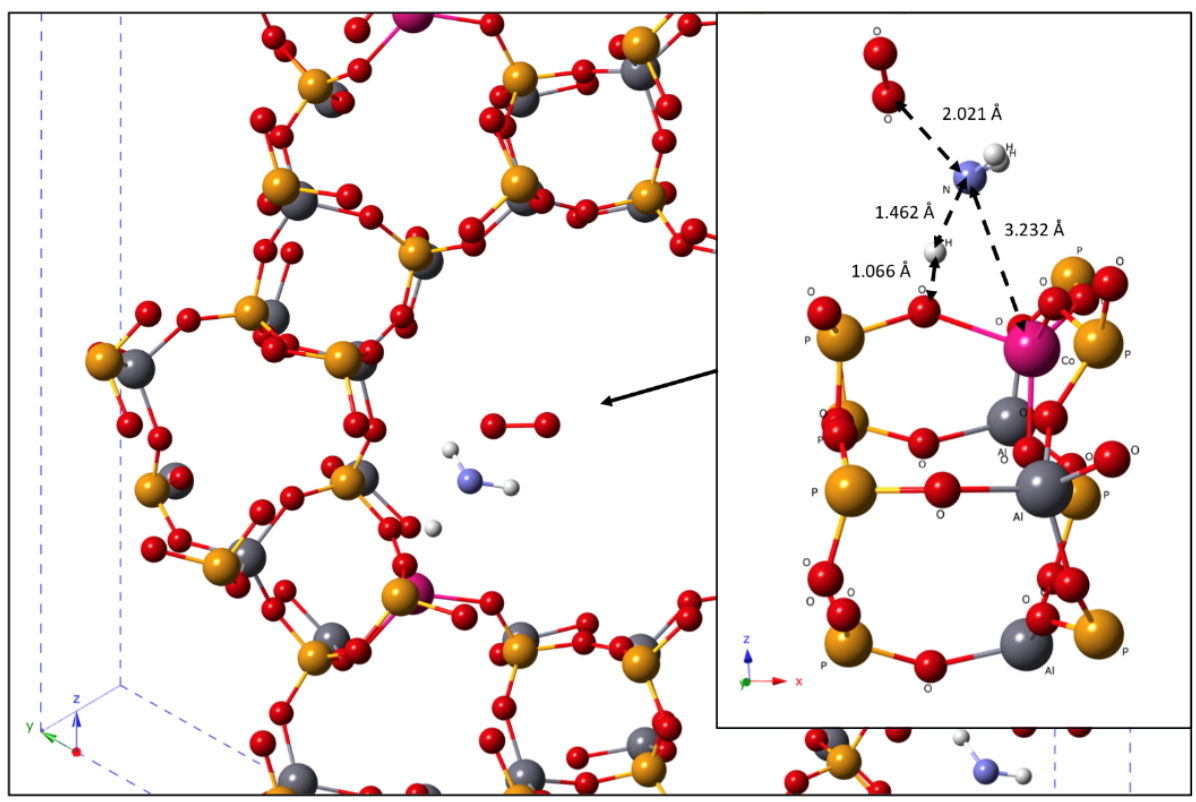

Figure S13: The calculated transition state for the monometallic CoAlPO- 5 system during the oxygen addition step. Pink $=$ Cobalt, Red $=$ Oxygen, Yellow $=$ Phosphorus, Grey $=$ Aluminium, White $=$ Hydrogen, Blue $=$ Nitrogen . 


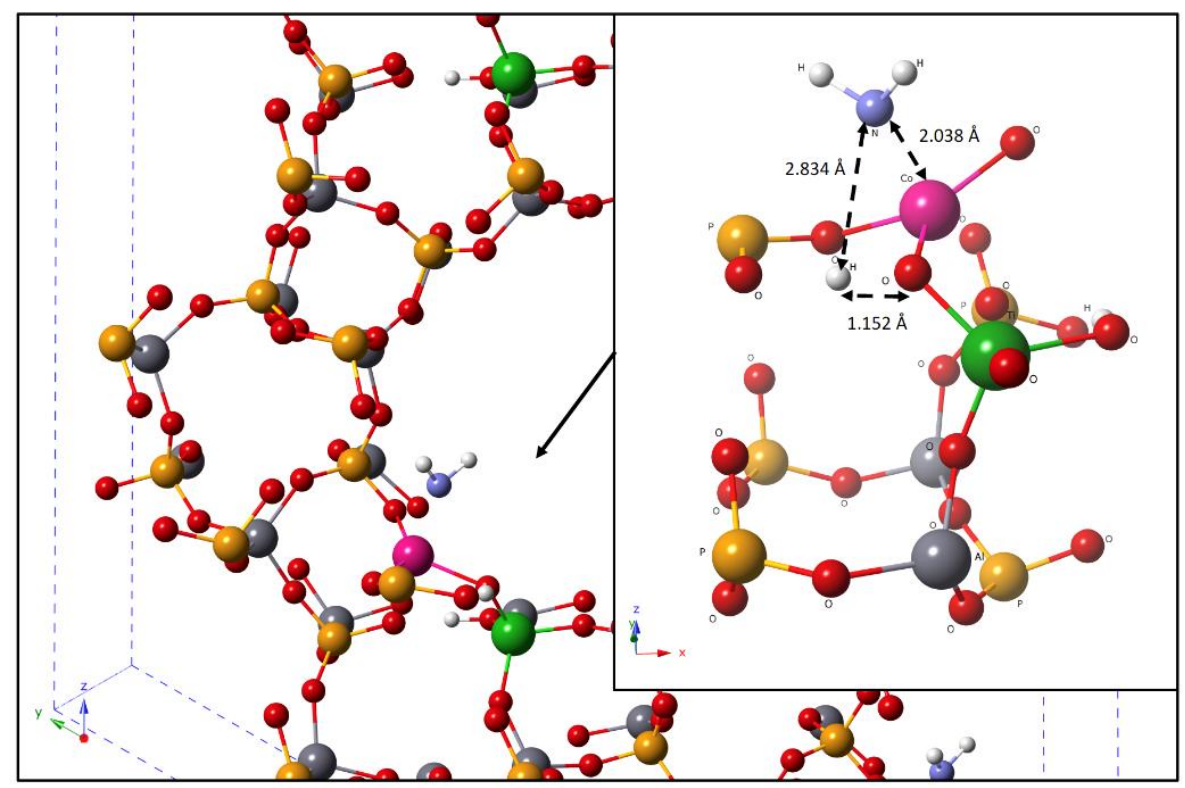

Figure S14: The calculated transition state for the bimetallic CoTiAlPO-5 system during the hydrogen abstraction step. Pink $=$ Cobalt, Green $=$ Titanium, Red $=$ Oxygen, Yellow $=$ Phosphorus, Grey $=$ Aluminium, White $=$ Hydrogen, Blue $=$ Nitrogen .

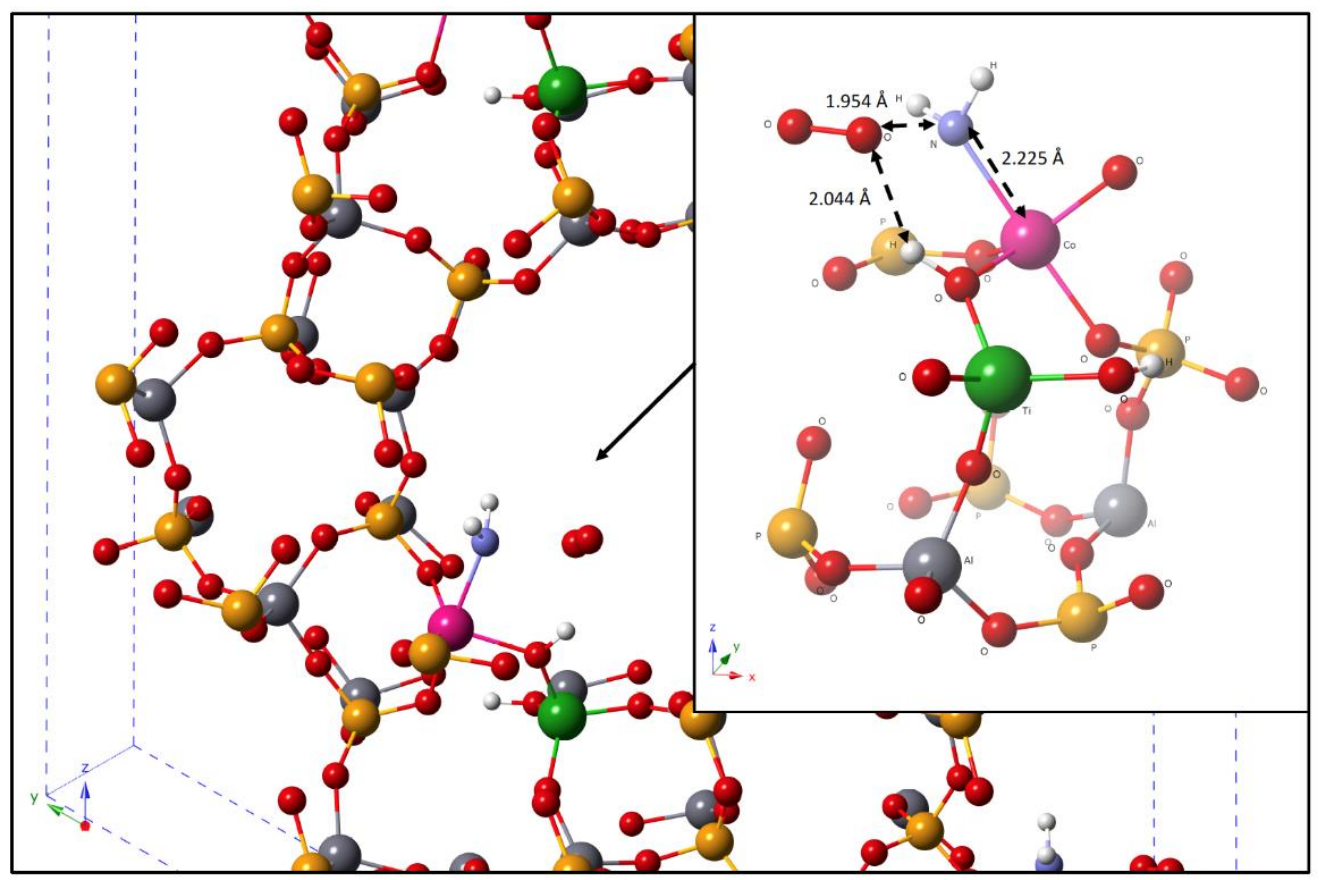

Figure S15: The calculated transition state for the bimetallic CoTiAlPO-5 system during the oxygen addition step. Pink $=$ Cobalt, Green $=$ Titanium, Red $=$ Oxygen, Yellow $=$ Phosphorus, Grey $=$ Aluminium, White $=$ Hydrogen, Blue $=$ Nitrogen . 


\section{Complete reaction energetics}

\section{Electronic energy + dispersion}

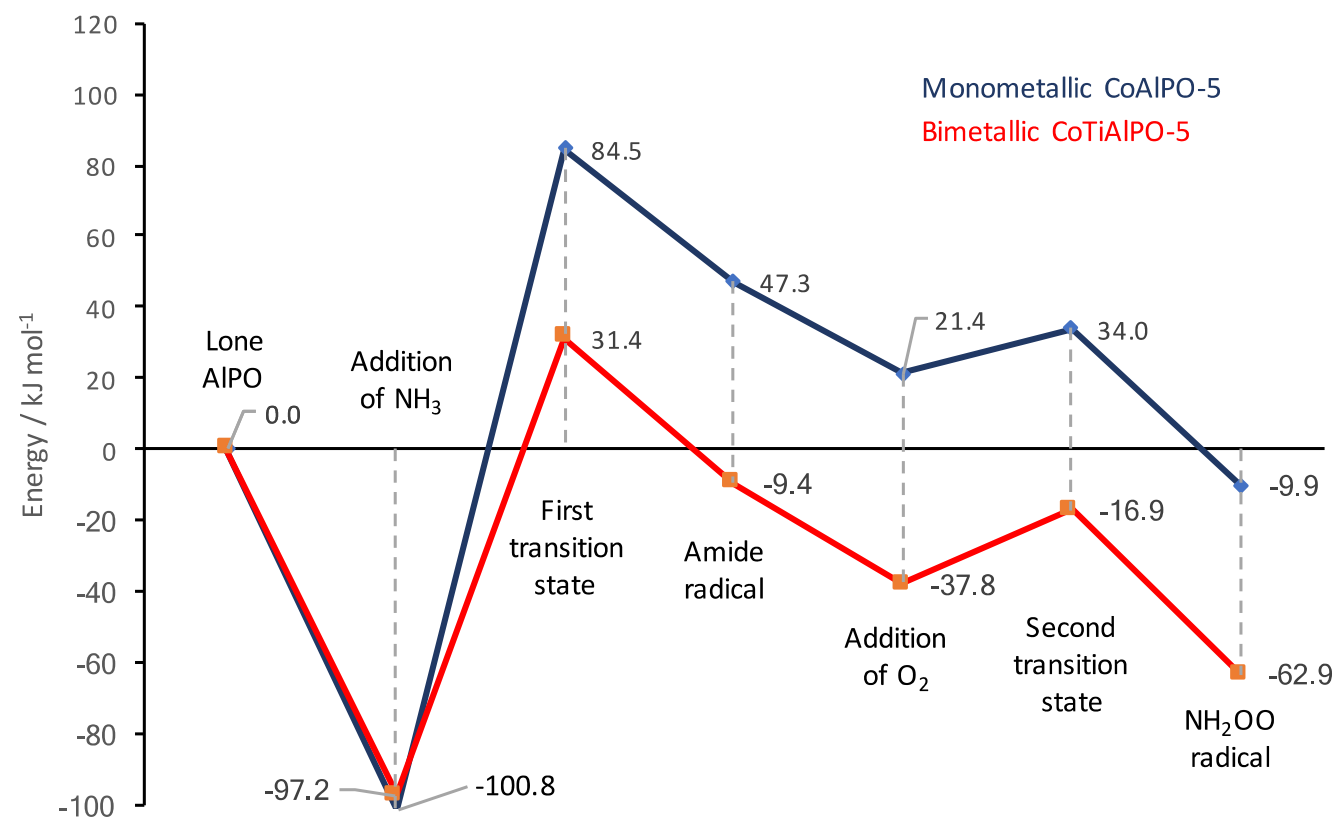

Figure S16: Full comparison of the complete electronic energetics required in the first two reaction steps, calculated with the addition of the dispersion correction.

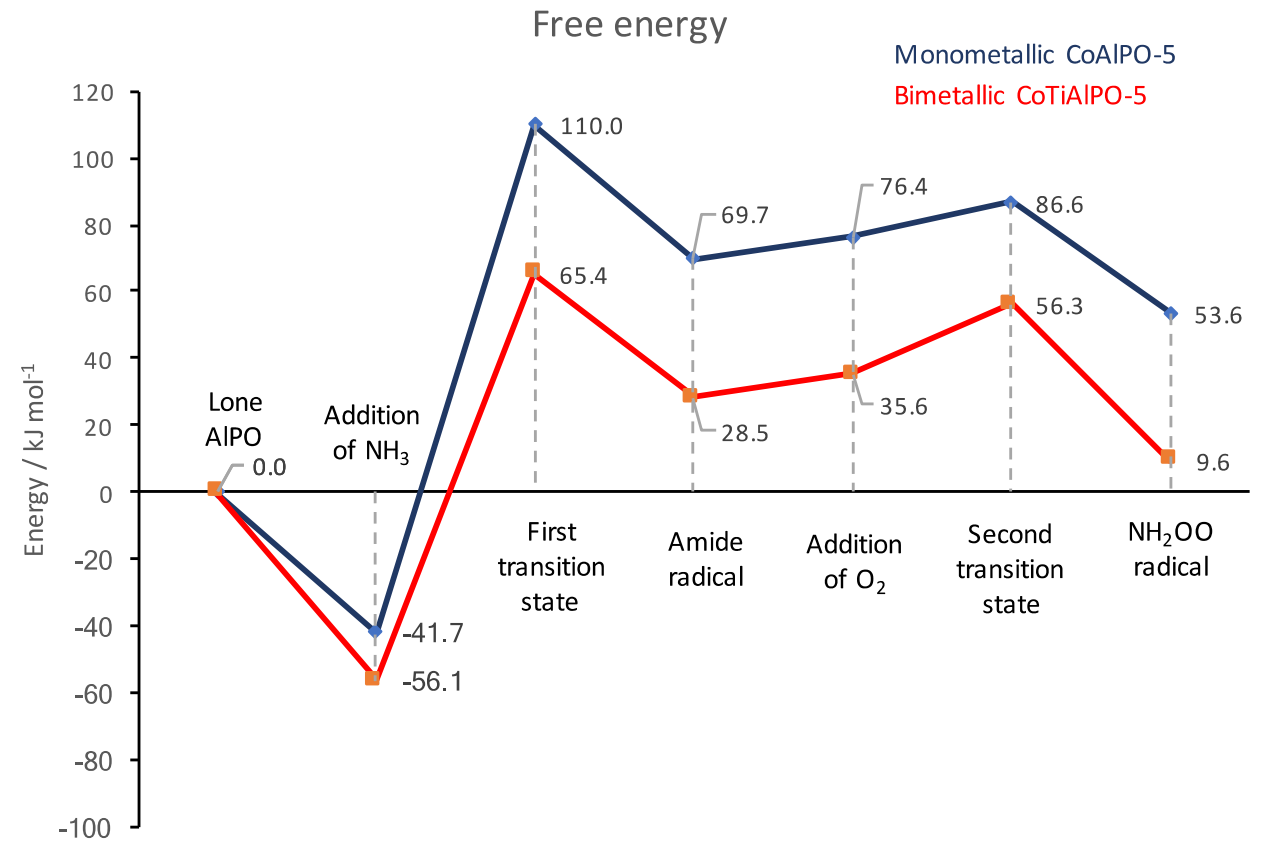

Figure S17: Full comparison of the complete free energy energetics required in the first two reaction steps, estimated by the addition of vibrational entropy and zero-point energy. 
Free energy + dispersion

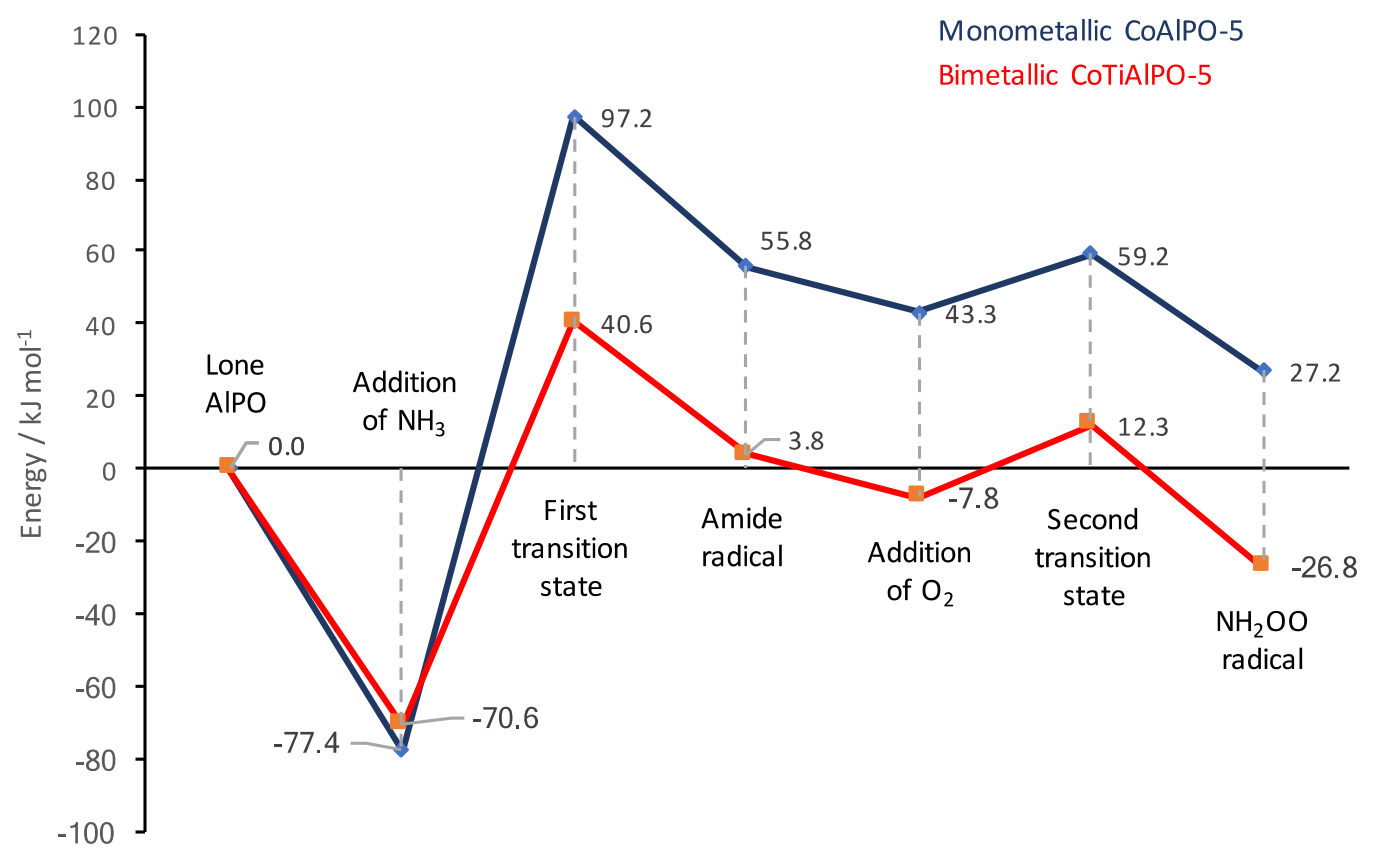

Figure S18: Full comparison of the complete free energy energetics required in the first two reaction steps, with the addition of the dispersion correction. 